\title{
G Protein-Coupled Estrogen Receptor Immunoreactivity in the Rat Hypothalamus Is Widely Distributed in Neurons, Astrocytes, and Oligodendrocytes, Fluctuates during the Estrous Cycle, and Is Sexually Dimorphic
}

\author{
Marilena Marraudino ${ }^{a} \quad$ Beatriz Carrillo $^{b}$ Brigitta Bonaldo $^{a}$ Ricardo Llorente $^{c}$ \\ Elia Campiolic Iciar Garate ${ }^{d}$ Helena Pinos $^{\text {b }}$ Luis Miguel Garcia-Segura ${ }^{e}$ \\ Paloma Collado ${ }^{b}$ Daniela Grassib, c, e \\ a Department of Neuroscience "Rita Levi Montalcini," Neuroscience Institute Cavalieri Ottolenghi, University \\ of Turin, Turin, Italy; ${ }^{b}$ Department of Psychobiology, Universidad Nacional de Educación a Distancia, Madrid, \\ Spain; ' Department of Preclinical Odontology, Universidad Europea de Madrid, Madrid, Spain; ${ }^{\mathrm{d}}$ Department of \\ Physiotherapy, Podology, and Dance, Universidad Europea de Madrid, Madrid, Spain; ' Instituto Cajal, CSIC, and \\ Centro de Investigación Biomédica en Red Fragilidad y Envejecimiento Saludable, Instituto de Salud Carlos III, \\ Madrid, Spain
}

\section{Keywords}

Arcuate nucleus · Lateral hypothalamus · Paraventricular nucleus · Supraoptic nucleus · Ventromedial hypothalamus

\footnotetext{
Abstract

Introduction: The membrane-associated $G$ protein-coupled estrogen receptor 1 (GPER) mediates the regulation by estradiol of arginine-vasopressin immunoreactivity in the supraoptic and paraventricular hypothalamic nuclei of female rats and is involved in the estrogenic control of hypothalamic regulated functions, such as food intake, sexual receptivity, and lordosis behavior. Objective: To assess GPER distribution in the rat hypothalamus. Methods: GPER immunoreactivity was assessed in different anatomical subdivisions of five selected hypothalamic regions of young adult male and cycling female rats: the arcuate nucleus, the lateral hypothalamus, the paraventricular nucleus, the supraoptic nucleus, and the ventromedial hypothalamic nucleus. GPER immunoreactivity was colocalized with $\mathrm{NeuN}$ as a marker of mature
}

neurons, GFAP as a marker of astrocytes, and CC1 as a marker of mature oligodendrocytes. Results: GPER immunoreactivity was detected in hypothalamic neurons, astrocytes, and oligodendrocytes. Sex and regional differences and changes during the estrous cycle were detected in the total number of GPER-immunoreactive cells and in the proportion of neurons, astrocytes, and oligodendrocytes that were GPER-immunoreactive. Conclusions: These findings suggest that estrogenic regulation of hypothalamic function through GPER may be different in males and females and may fluctuate during the estrous cycle in females.

(c) 2020 S. Karger AG, Basel

\section{Introduction}

G protein-coupled estrogen receptor 1 (GPER), formerly referred as $G$ protein-coupled receptor 30 , is expressed in the central nervous system and in peripheral tissues and participates in physiological and pathological events regulated by estradiol in the nervous, immune, re- karger@karger.com

(C) 2020 S. Karger AG, Basel

www.karger.com/nen

Karger ${ }^{\prime}=$
Daniela Grassi

Department of Preclinical Odontology, Universidad Europea de Madrid Calle Tajo s/n

ES-28670 Villaviciosa de Odon, Madrid (Spain)

dada.grassi@gmail.com or daniela.grassi@universidadeuropea.es 
productive, and cardiovascular systems [1]. In the central nervous system GPER has been localized in neurons [2$6]$, astrocytes [3, 5-7], oligodendrocytes [8, 9], and endothelial cells [10].

In neurons, GPER activation causes membrane depolarization $[11,12]$, regulates synaptic transmission, neurotransmitter release, and synaptic plasticity [13-16], and mediates the estrogenic regulation of different signaling mechanism, including the production of cAMP, the activation of PI3K/Akt and ERK, and the inhibition of JNK and the increase in cytosolic $\mathrm{Ca}^{2+}$ levels $[11,12,17-20]$. In astrocytes, GPER regulates autophagy [21] and mediates the effects of estradiol on the upregulation of intracellular $\mathrm{Ca}^{2+}$ concentration, glutamate transporter expression, and the uptake of glutamate $[6,22]$. In oligodendrocytes, GPER participates in the process of myelination and remyelination $[9,23]$. Finally, in brain endothelial cells, GPER activates protein kinase A, resulting in the induction of $\mathrm{Ca}^{2+}$ influx via L-type $\mathrm{Ca}^{2+}$ channels, which in turn increases membrane hyperpolarization, nitric oxide production, and cell stiffness [10].

These cellular and molecular events regulated by GPER participate in the behavioral consequences of the activation of this receptor, such as the regulation of social behavior and hippocampal memory $[16,24,25]$. In addition, GPER mediates estrogenic actions involving the hypothalamus, such as the control of food intake in male mice [26] and the regulation of sexual receptivity [27], and lordosis behavior in female rats [28-30]. Furthermore, GPER participates in the estrogenic regulation of arginine-vasopressin immunoreactivity, NADPH diaphorase expression, and ERK phosphorylation in the supraoptic and paraventricular hypothalamic nuclei of female rats $[31,32]$. These effects may be mediated by direct actions of estradiol on hypothalamic GPER receptors. Indeed, GPER immunoreactivity has been detected in the hypothalamus of rats [27, 29,33-36], mice [37], hamsters [38], and monkeys [39].

Although the expression of GPER in the hypothalamus is well established, its precise cellular and anatomical distribution among different hypothalamic regions still remains to be fully characterized. Therefore, in this study we analyzed the distribution of GPER-immunoreactive neurons, astrocytes, and oligodendrocytes in different anatomical subdivisions of five selected hypothalamic regions of the rat brain: the arcuate nucleus, the lateral hypothalamus, the paraventricular nucleus, the supraoptic nucleus, and the ventromedial hypothalamic nucleus. Furthermore, we analyzed the possible differences in GPER immunoreactivity between male animals and fe- males in estrus and diestrus 2 (i.e., 24 and $72 \mathrm{~h}$ after the peak of estradiol in proestrus, respectively), since previous studies have detected sex differences in GPER mRNA distribution in the hypothalamus and other brain regions of hamsters [38] and differences in the expression of GPER in the rat brain during the estrous cycle [40]. Our findings indicate that hypothalamic GPER immunoreactivity is widely distributed in neurons, astrocytes, and oligodendrocytes, shows significant regional and sex differences, and fluctuates during the female estrous cycle.

\section{Materials and Methods}

\section{Animals and Experimental Treatments}

Wistar albino male and female rats from our in-house colony were kept on a 12:12-h light-dark cycle and received food and water ad libitum. Twenty-four adult rats aged 2 months ( 8 males and 16 females) were housed separately in plastic cages. After 2 weeks of habituation and handling, monitoring of the estrous cycle in female rats was performed between 8:00 to 10:00 a.m. during 7 days by vaginal smears $[41,42]$. On day 7 , female rats were tested for the last vaginal smear in order to define the experimental group. Females were studied in estrus or in diestrus 2 . We selected females in estrus, 1 day after the peak of estradiol in proestrus, and in diestrus 2. Subsequently all animals, male and female, were deeply anesthetized with pentobarbital $50 \mathrm{mg} / \mathrm{kg}$ (Normon Veterinary Division, Madrid, Spain) between 8:00 and 10:00 a.m. and perfused through the left cardiac ventricle with $50 \mathrm{~mL}$ of saline solution $(0.9 \% \mathrm{NaCl})$ followed by $250 \mathrm{~mL}$ of fixative solution $(4 \%$ paraformaldehyde in $0.1 \mathrm{M}$ phosphate buffer, $\mathrm{pH}$ 7.4). Brains were quickly removed and immersed for $4-6 \mathrm{~h}$ at $4^{\circ} \mathrm{C}$ in the same fixative solution and then rinsed with phosphate buffer. Brains were placed for $72 \mathrm{~h}$ in a $30 \%$ sucrose solution in PBS, frozen in liquid isopentane at $-35^{\circ} \mathrm{C}$, and stored in a deep freezer at $-80^{\circ} \mathrm{C}$ until sectioning. Brains were serially cut in the coronal plane at $20 \mu \mathrm{m}$ thickness with a cryostat, obtaining five series of adjacent serial sections. In each series, each section was $100 \mu \mathrm{m}$ distant from the following one. The plane of sectioning was oriented to match the drawings corresponding to the transverse sections of the rat brain atlas of Paxinos and Watson [43]. Sections were collected in multiwell plates with a cryoprotectant solution [44] and kept at $-20^{\circ} \mathrm{C}$. Immunohistochemical assay for GPER was performed on different series. One of each five consecutive sections was stained with $0.1 \%$ cresyl violet ( $\mathrm{pH}$ 7.4) to facilitate the identification of the hypothalamic structures.

\section{Immunohistochemistry}

The presence of GPER was detected by immunohistochemistry performed on free-floating sections according to the following steps. Before the reaction, the sections collected in the cryoprotectant solution were washed overnight at $4{ }^{\circ} \mathrm{C}$ in PBS $0.1 \mathrm{M}, \mathrm{pH} 7.3-$ 7.4. The following day, free-floating sections were first washed for 30 min at room temperature in PBS $0.1 \mathrm{M}, \mathrm{pH} 7.3-7.4$, containing $0.2 \%$ Triton X-100 and $0.2 \%$ BSA. Sections were then treated for 10 min with a solution of PBS $0.1 \mathrm{M}, \mathrm{pH} 7.3-7.4$, containing methanol/hydrogen peroxide (PBS/methanol 1:1 with $0.3 \%$ hydrogen 
Fig. 1. Representative examples of GPER immunohistochemical localization in rat hypothalamic sections. GPER immunoreactivity was widely distributed in the hypothalamus. a GPER-immunoreactive cells were detected in the paraventricular nucleus (PVN) and supraoptic nucleus (SON). b GPER immunoreactivity in the lateral hypothalamus (LH), ventromedial hypothalamus $(\mathrm{VMH})$, and arcuate nucleus (ARC) among other hypothalamic regions. c GPER immunostaining using a preabsorbed antibody with the specific blocking peptide. d At high magnification immunoreactivity showed a cytoplasmic localization. All figures are from females in estrus. Asterisks denote optic fibers. Scale bars, $200 \mu \mathrm{m}$ in $\mathbf{a}, \mathbf{b}$, and $\mathbf{d}$ and $20 \mu \mathrm{m}$ in c. GPER, $G$ protein-coupled estrogen receptor 1; III, third ventricle.
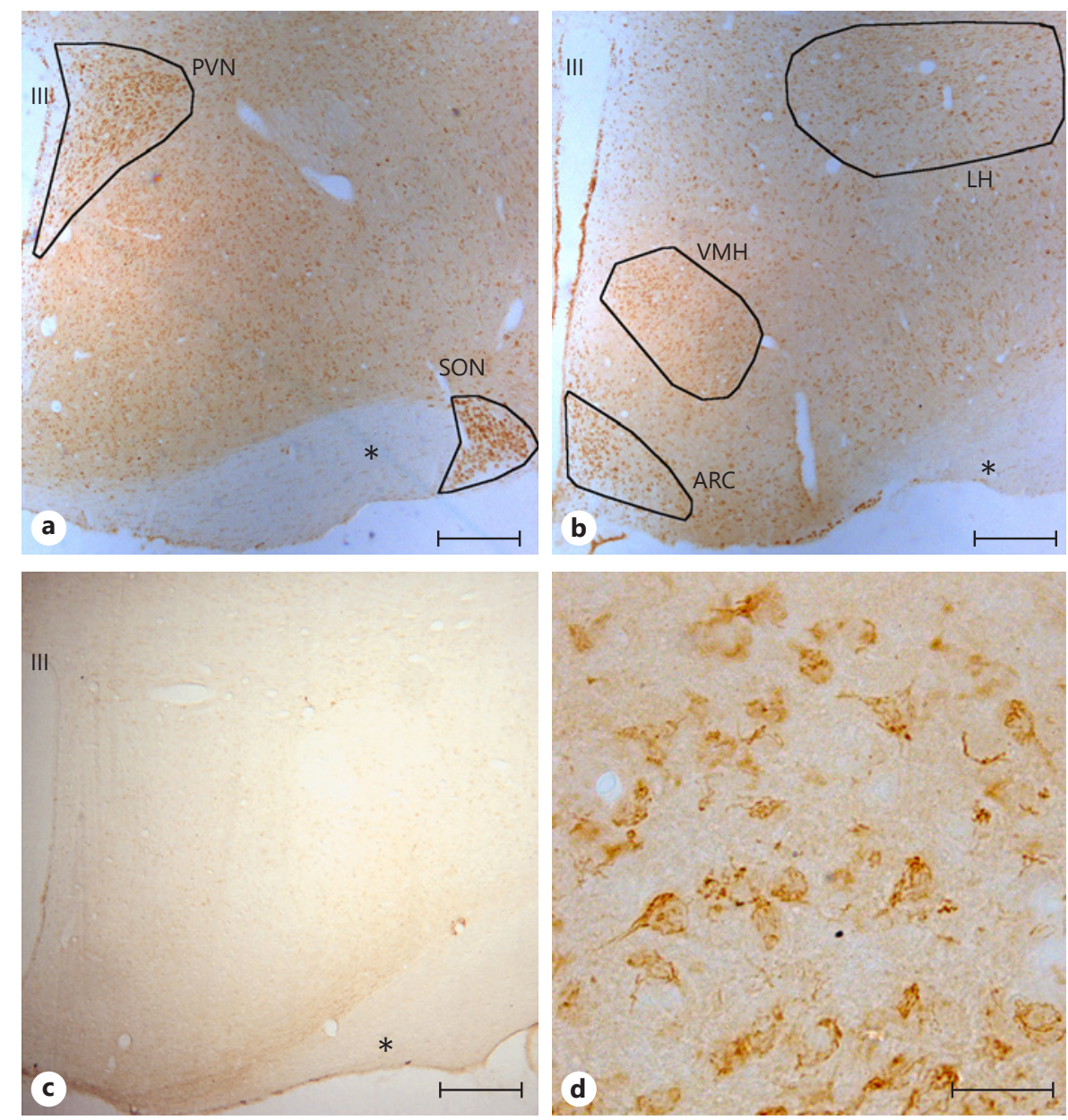

peroxide) to quench endogenous peroxidase activity. Sections were washed for $30 \mathrm{~min}$ at room temperature in PBS $0.1 \mathrm{M}, \mathrm{pH}$ 7.3-7.4, containing $0.2 \%$ Triton X-100 and $0.2 \%$ BSA and then incubated for $48 \mathrm{~h}$ at $4{ }^{\circ} \mathrm{C}$ with a rabbit polyclonal GPER antibody (Abcam, Cambridge, UK; reference ab39742; antibody register RRID:AB_1141090) diluted 1:250 in 0.1 M PBS, pH 7.3-7.4, containing $0.2 \%$ Triton $\mathrm{X}-100,0.2 \% \mathrm{BSA}$, and $3 \%$ normal serum goat. A biotinylated goat antirabbit secondary antibody (Thermo Scientific, Pierce, Rockford, IL, USA) was then used at a dilution of 1:300 for $120 \mathrm{~min}$ at room temperature. The antigen-antibody reaction was revealed by incubation with avidin-peroxidase complex (Thermo Scientific, Pierce) for $90 \mathrm{~min}$. The peroxidase activity was visualized with a solution containing $0.187 \mathrm{mg} / \mathrm{mL} \mathrm{3,3-diamino-}$ benzidine (Sigma, Madrid, Spain) in PBS 0.1 M, pH 7.3-7.4. The sections were washed in the same buffer and collected on chromallum-coated slides, air dried, cleared in xylene, and coverslipped with Depex (VWR International Eurolab, Barcelona, Spain) for quantitative analysis. According to the manufacturer's information, the GPER antibody results in a single band of $55 \mathrm{kDa}$ in Western blots of human brain tissue lysates (www.abcam. com/g-protein-coupled-receptor-30-antibody-ab39742.html). In agreement with this, the antibody labels a $55-\mathrm{kDa}$ band in Western blots of mouse [45] and rat hippocampus [46]. This GPER anti- body has been extensively used for the determination of GPER levels and/or cellular localization in a variety of tissues, including Western blot [45-48] and immunohistochemical analyses [31, 46$50]$ of mouse and rat central nervous system. Previous studies have validated the immunohistochemical localization of this antibody in rat brain sections by preabsorption experiments $[31,48]$. In agreement with our previous findings on rat hypothalamus [31], GPER immunostaining was absent in hypothalamic sections preincubated with the GPER-blocking peptide (Fig. 1). Immunostaining in our histological preparations was also absent when the incubation with the first antibody was omitted (not shown).

\section{Immunofluorescence}

The presence of GPER, NeuN as a marker of mature neurons [51], GFAP as a marker of astrocytes [52], and CC1 (OP80) as a marker of mature oligodendrocytes [53] was assessed on one series each using 3 animals as experimental group. Before the NeuN and CC-1 immunostainings, antigen retrieval was performed first treating the sections with citrate buffer $(\mathrm{pH} \mathrm{6})$ for $20 \mathrm{~min}$ at $95^{\circ} \mathrm{C}$. The sections were then washed with PBS $0.1 \mathrm{M}, \mathrm{pH} 7.3-7.4$, containing $0.5 \%$ Triton X-100 (Merck, Darmstadt, Germany) for $30 \mathrm{~min}$ at room temperature. After washing, sections were first incubated at room temperature for $1 \mathrm{~h}$ with blocking solution 
Table 1. List of primary and secondary antibodies used for immunohistochemistry

\begin{tabular}{|c|c|c|c|c|}
\hline Antigen & Code & Source & Host, clonality & Dilution \\
\hline \multicolumn{5}{|l|}{ Primary antibodies } \\
\hline GPR30 & ab39742 & Abcam & rabbit, $\mathrm{pc}$ & $1: 100$ \\
\hline NeuN & MAB377 & Millipore & mouse, mc & $1: 250$ \\
\hline GFAP & MAB360 & EMD Millipore & mouse, mc & $1: 1,000$ \\
\hline CC1 & OP80 & Calbiochem & mouse, mc & $1: 1,000$ \\
\hline \multicolumn{5}{|l|}{ Secondary antibodies } \\
\hline Antirabbit Alexa Fluor ${ }^{\circledR} 488$ & $111-545-144$ & Jackson ImmunoResearch Labs & goat, pc & $1: 500$ \\
\hline Antimouse Alexa Fluor ${ }^{\circledR} 647$ & $115-605-146$ & Jackson ImmunoResearch Labs & goat, pc & $1: 500$ \\
\hline
\end{tabular}

containing $0.5 \%$ Triton X-100, 1\% BSA (Sigma-Aldrich), and 1\% normal goat serum (Vector Laboratories) diluted in PBS $0.1 \mathrm{M}, \mathrm{pH}$ 7.3-7.4 and afterward incubated overnight with primary antibodies (Table 1) diluted in blocking solution. Then, sections were washed with PBS 0.1 M, pH 7.3-7.4 and incubated for $2 \mathrm{~h}$ with secondary antibodies (Table 1) and 4',6-diamidino-2-phenylindole $(1: 1,000)$, used to reveal nuclei, diluted in PBS $0.1 \mathrm{M}, \mathrm{pH}$ 7.3-7.4. Sections were finally coverslipped with Mowiol antifade mounting medium (Sigma-Aldrich). The NeuN (Millipore Cat. No. MAB377, RRID:AB_2298772), GFAP (Millipore Cat. No. MAB360, RRID:AB_11212597), and OP80 (Millipore Cat. No. OP80, RRID:AB_2057371) antibodies have been extensively used and validated for the immunohistochemical localization of neurons, astrocytes, and oligodendrocytes, respectively (see RRIDAB_2298772, RRID:AB_11212597, and RRID:AB_2057371 for references). The NeuN antibody recognizes RNA-binding Fox-3 protein, which is involved in the regulation of alternative splicing of pre-RNA [54]. The OP80 antibody has been shown to recognize Quaking 7 [53], a RNA-binding protein that is highly expressed by myelinating oligodendrocytes. Immunostaining was absent in hypothalamic sections in which the primary antibodies were omitted.

\section{Morphometric Analysis}

The quantitative analysis of GPER was performed on coded sections without knowledge of the experimental group. Selected fields were acquired by a digital camera (Olympus DP25) connected to a Nikon eclipse E600 microscope using $\times 20$ and $\times 10$ objectives. The number of GPER-positive cells was assessed in the arcuate nucleus, lateral hypothalamus, paraventricular nucleus, supraoptic nucleus, and ventromedial hypothalamus using four coded sections per animal. Only tissue blocks in which the anatomical integrity of the hypothalamic nuclei in consideration was fully preserved were included in the analysis. All cells showing a cell nucleus were included for quantification in SAB-stained sections. Thus, both neurons and nonneuronal cells were included in the counts. Data presented for each hypothalamic region are the sum of the number of GPER-immunolabeled cells in the four sections per rat.

\section{Neuroanatomical Analysis}

Sections selected for analysis corresponded to the following plates from the rat brain atlas of Paxinos and Watson [43]: plate 23 for the supraoptic nucleus, plate 26 for the paraventricular nucleus, plate 29 for the ventromedial and lateral hypothalamus, and plate 31 for the arcuate nucleus.

\section{Cell Counts}

Counts were restricted to the right hemisphere of the hypothalamus. Given the anatomical heterogeneity of the paraventricular nucleus, a grid of 24 square boxes of $8 \mu \mathrm{m}^{2}$ each was used to delimit regions of interest within each subdivision of the nucleus. The grid was precisely located, ensuring the left side of the grid on the wall of the third ventricle. The grid overlapped the total area of the paraventricular nucleus. Cell counting was performed for each square box within the boundaries of the nucleus and cells were counted only in those squares that were completely located within the nucleus. The paraventricular nucleus was subdivided into the paraventricular dorsal cap $(\mathrm{PaDC})$, the paraventricular lateral magnocellular subdivision (PaLM), the paraventricular medial magnocellular subdivision ( $\mathrm{PaMM}$ ), and the paraventricular parvocellular subdivision $(\mathrm{PaV})$. These subdivisions were identified following the anatomical description provided for the rat by Armstrong et al. [55] based on Nissl-stained material. The boxes corresponding to the same subdivision of the paraventricular nucleus, along the four coded sections, were grouped for statistical analysis [56]. In the supraoptic nucleus, instead, all GPER-positive cells within the anatomical boundaries of the nucleus were counted together. Standardized serial sections of comparable level were selected to count GPER-positive cells in the arcuate nucleus, using a predetermined region of interest (a square of $889,728 \mu \mathrm{m}^{2}$ ). The region of interest was placed within the boundaries of the nucleus to cover the immunopositive region; we used as reference the third ventricle to always position the square in the same orientation. The same analysis was performed for the GPER-IR cells in the lateral hypothalamus and the ventromedial nucleus, where the region of interest followed the boundaries of the nuclei. The ventromedial nucleus was subdivided into three regions - dorsomedial, central, and ventrolateral - according the rat atlas of Paxinos and Watson [43].

\section{Statistical Analysis}

Data were analyzed by one-way ANOVA followed by the Bonferroni post hoc test using the SPSS 17.0 software (SPSS Inc., Chicago, IL, USA). A $p$ value $<0.05$ was considered statistically significant. Data are presented as mean \pm SEM. 


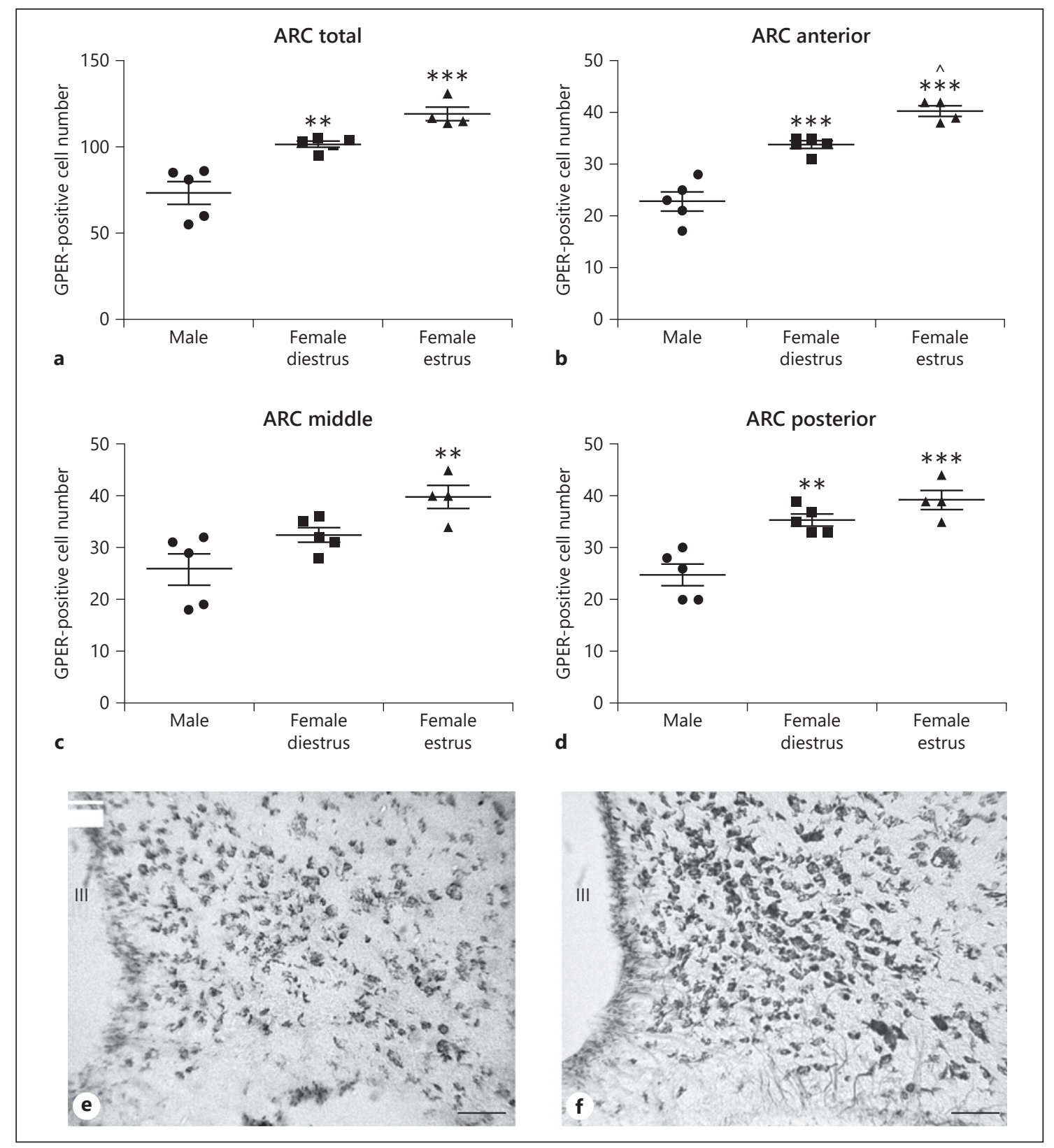

Fig. 2. Number of GPER-immunoreactive cells in the arcuate nucleus (ARC) of male $(n=5)$, diestrous female $(n=5)$, and estrous female $(n=4)$ rats. a ARC as a whole. b Anterior portion of the ARC. c Middle portion of the ARC. d Posterior portion of the ARC. Data are presented as mean \pm SEM. ${ }^{* *}, * * *$ Significant differences $\left({ }^{* *} p<0.01,{ }^{* * *} p<0.001\right)$ versus male values. ^ Significant difference $(p<0.05)$ versus females in diestrus. e Representative microphotograph of GPER immunoreactivity in the ARC of a male rat. $\mathbf{f}$ Representative microphotograph of GPER immunoreactivity in the ARC of a female rat in estrus. Scale bar, $100 \mu \mathrm{m}$. GPER, G proteincoupled estrogen receptor 1 ; III, third ventricle.

\section{Results}

\section{GPER-Positive Cells in Hypothalamic Nuclei}

Examples of GPER immunoreactivity in the rat hypothalamus are shown in Figure 1. Immunoreactivity showed a cytoplasmic localization and was widely distributed, delineating the main hypothalamic nuclei, such as the paraventricular nucleus, the supraoptic nucleus, the arcuate nucleus, the ventromedial hypothalamus, and the lateral hypothalamus (Fig. 1a, b, d). GPER immunoreac- 


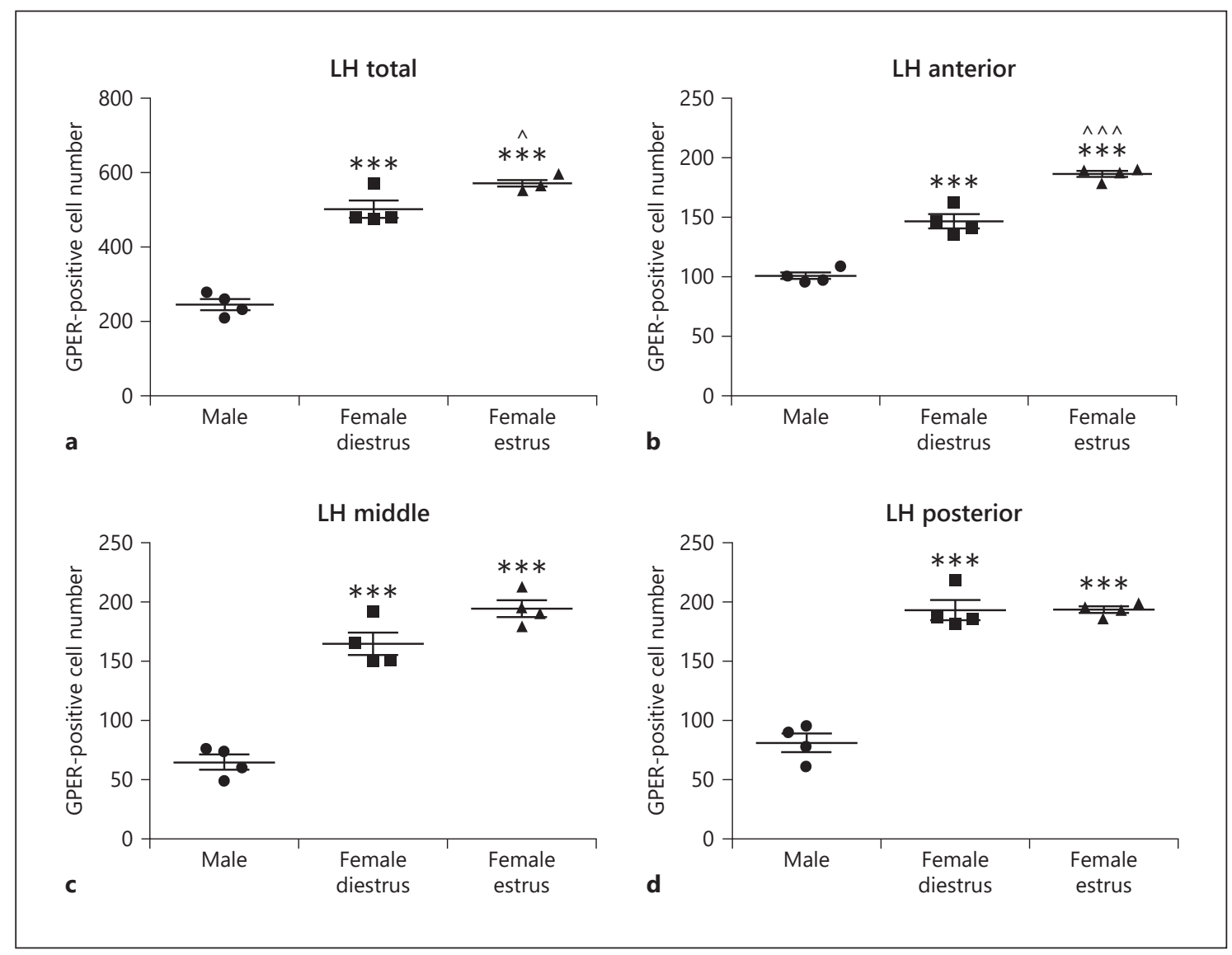

Fig. 3. Number of GPER-immunoreactive cells in the lateral hypothalamus (LH) of male $(n=5)$, diestrous female $(n=4)$, and estrous female $(n=4)$ rats. a LH as a whole. $\mathbf{b}$ Anterior portion of the LH. c Middle portion of the LH. d Posterior portion of the LH. Data are presented as mean \pm SEM. *** Significant differences $(p<0.001)$ versus male values. $\wedge, \wedge \wedge \wedge$ Significant differences $(\wedge p<0.05, \wedge \wedge \wedge p<0.001)$ versus females in diestrus. GPER, G protein-coupled estrogen receptor 1 .

tivity was not detected in hypothalamic sections preincubated with the GPER-blocking peptide (Fig. 1c).

\section{GPER Immunostaining in the Arcuate Nucleus}

Quantitative analysis revealed sex differences in the number of GPER-immunoreactive cells in the arcuate nucleus, with higher values in female animals compared to males (Fig. 2). ANOVA revealed a significant difference among experimental groups when data from the three portions of the arcuate nucleus were pooled $\left(F_{(2,13)}=\right.$ 23.88; $p<0.0001$; Fig. 2a). This difference was also detected when the data from the three portions of the arcuate nucleus were separately analyzed: anterior $\left(F_{(2,13)}=\right.$ $42.31 ; p<0.0001$; Fig. $2 b)$, middle $\left(F_{(2,13)}=8.363 ; p<0.01\right.$; Fig. $2 c)$, and posterior $\left(F_{(2,13)}=18.73 ; p<0.001\right.$; Fig. $\left.2 d\right)$.

Post hoc analysis revealed that females in diestrus showed a higher number of GPER-immunoreactive cells than males in the whole nucleus $(p<0.01)$ and its anterior $(p<0.001)$ and posterior $(p<0.01)$ portions. Females in estrus also showed a higher number of GPER-immunoreactive cells than males in the whole nucleus $(p<0.001)$ and in its anterior $(p<0.001)$, middle $(p<0.05)$, and posterior $(p<0.001)$ subdivisions (Fig. 2c). Furthermore, in the anterior part of the arcuate nucleus, females in estrus showed a higher number of GPER-immunoreactive cells than females in diestrus $(p<0.05$; Fig. 2b).

Representative microphotograph of GPER immunoreactivity in the arcuate nucleus of a male rat and a female rat in estrus are shown in Figure 2e and f, respectively.

GPER Immunostaining in the Lateral Hypothalamus

Similar to the arcuate nucleus, the lateral hypothalamus showed sex differences in GPER immunoreactivity, 


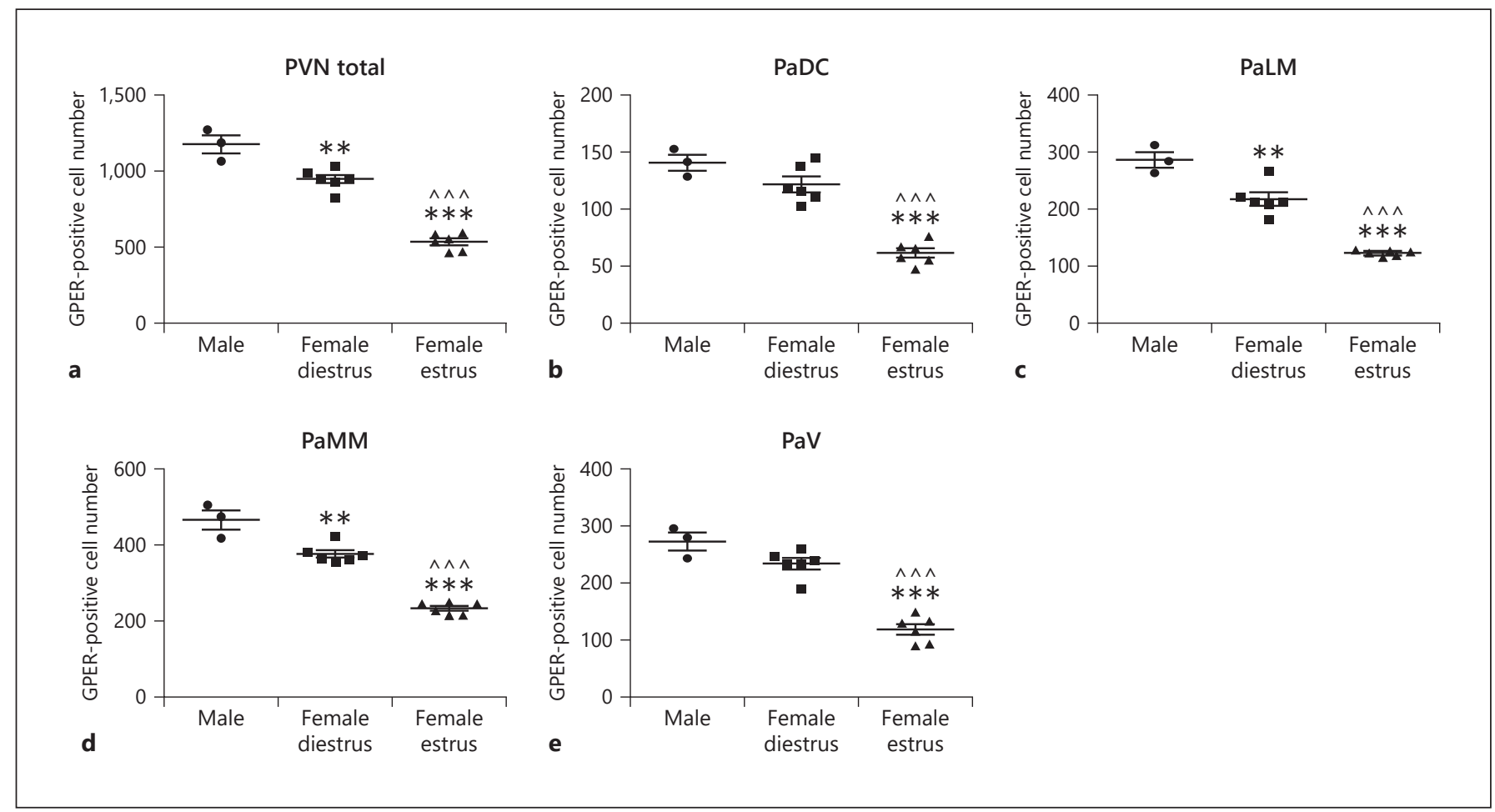

Fig. 4. Number of GPER-immunoreactive cells in the paraventricular nucleus (PVN) of male $(n=3)$, diestrous female $(n=4)$, and estrous female $(n=4)$ rats. a PVN as a whole. b PaDC. c PaLM. d PaMM. e PaV. Data are presented as mean \pm SEM. **,*** Significant differences $\left(* * p<0.01,{ }^{* * *} p<0.001\right)$ versus male values.

with a higher number of GPER-immunopositive cells in female animals compared to males. As for the arcuate nucleus, ANOVA revealed a significant difference among experimental groups in the number of GPER-immunoreactive cells in the whole lateral hypothalamus $\left(F_{(2,11)}=106.1 ; p<0.001\right.$; Fig. 3a). This difference was detected in the three subdivisions of the lateral hypothalamus: anterior $\left(F_{(2,11)}=110.8 ; p<0.001\right.$; Fig. $\left.3 b\right)$, middle $\left(F_{(2,11)}=74.12 ; p<0.001\right.$; Fig. $\left.3 \mathrm{c}\right)$, and posterior $\left(F_{(2,11)}=93.05 ; p<0.001\right.$; Fig. $\left.3 \mathrm{~d}\right)$.

Post hoc analysis revealed that females in diestrus had a higher number of GPER-immunoreactive cells than males in the whole nucleus $(p<0.001)$ and its anterior $(p<0.001)$, middle $(p<0.001)$, and posterior $(p<0.001)$ portions. Females in estrus also showed a higher number of GPER-immunoreactive cells $(p<0.001)$ in all subdivisions of the lateral hypothalamus than males. In addition, females in estrus had a higher number of GPER-immunoreactive cells in the whole lateral hypothalamus $(p<$ 0.05 ) compared to females in diestrus (Fig. 3a). This dif- $\wedge \wedge \wedge$ Significant differences $(p<0.001)$ versus females in diestrus. GPER, G protein-coupled estrogen receptor 1; $\mathrm{PaDC}$, paraventricular dorsal cap; PaLM, paraventricular lateral magnocellular subdivision; PaMM, paraventricular medial magnocellular subdivision; $\mathrm{PaV}$, paraventricular parvocellular subdivision. ference was due to GPER cells located in the anterior part of the nucleus ( $p<0.001$; Fig. $3 b)$.

\section{GPER Immunostaining in the Paraventricular \\ Nucleus}

In the paraventricular nucleus, males had a higher number of GPER-immunoreactive cells than females in diestrus and estrus. ANOVA revealed a significant difference among experimental groups in the number of GPERimmunoreactive cells in the whole nucleus $\left(F_{(2,14)}=93.75\right.$; $p<0.001$; Fig. 4a). This difference was detected in the four subdivisions of the paraventricular nucleus (see Materials and Methods): $\operatorname{PaDC}\left(F_{(2,14)}=46.09 ; p<0.001\right.$; Fig. $\left.4 \mathrm{~b}\right)$, $\operatorname{PaLM}\left(F_{(2,14)}=68.04 ; p<0.001\right.$; Fig. $\left.4 \mathrm{c}\right), \operatorname{PaMM}\left(F_{(2,14)}=\right.$ 90.75; $p<0.001$; Fig. 4 d), and $\mathrm{PaV}\left(F_{(2,14)}=52.51 ; p<\right.$ 0.001; Fig. 4e).

Males had a higher number of GPER-immunoreactive cells in the whole nucleus $(p<0.01), \operatorname{PaLM}(p<0.01)$, and PaMM $(p<0.01)$ compared to females in diestrus (Fig. 4a, $c, d$, respectively). They also had a higher number of 
Fig. 5. Representative microphotographs of GPER immunoreactivity in the paraventricular nucleus. a Male rat. b Female rat in estrus. Scale bars, $100 \mu \mathrm{m}$. GPER, G protein-coupled estrogen receptor 1; III, third ventricle.
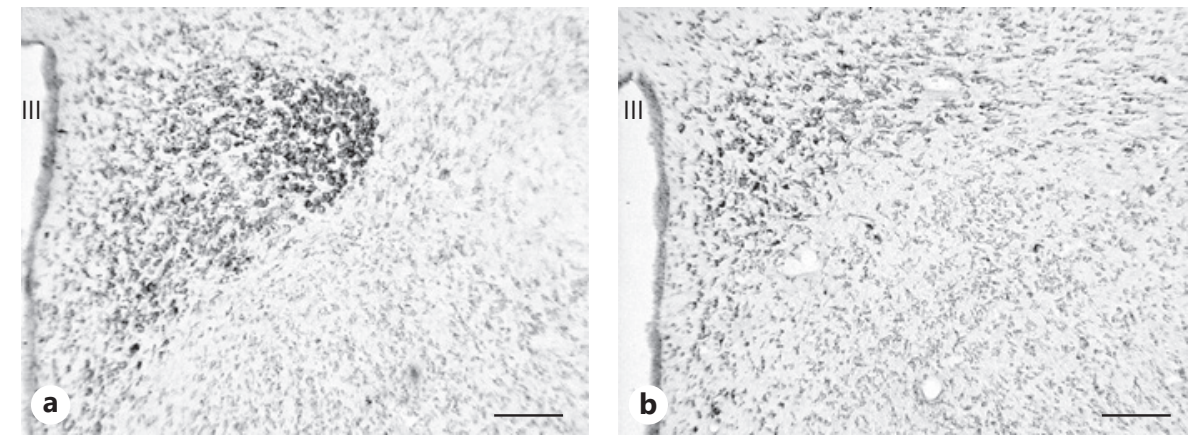

GPER-immunoreactive cells in the four subdivisions of the nucleus $(p<0.001)$ compared to females in estrus (Fig. $4 \mathrm{a}-\mathrm{e}$ ). In addition, females in estrus showed a lower number of GPER-immunoreactive cells than females in diestrus $(p<0.001)$ in the four subdivisions of the paraventricular nucleus (Fig. $4 \mathrm{a}-\mathrm{e}$ ).

Representative microphotographs of GPER immunoreactivity in the paraventricular nucleus of a male rat and a female rat in estrus are shown in Figure $5 a$ and b, respectively.

\section{GPER Immunostaining in the Supraoptic Nucleus}

In the supraoptic nucleus we observed a higher number of GPER-immunoreactive cells in males compared to females in diestrus. ANOVA revealed a significant difference among experimental groups in the number of GPERimmunoreactive cells in the whole nucleus $\left(F_{(2,14)}=45.18\right.$; $p<0.001$; Fig. 6a). This difference was detected in the three portions of the supraoptic nucleus: anterior $\left(F_{(2,14)}=\right.$ 4.605 ; $p<0.05$; Fig. 6b), middle $\left(F_{(2,14)}=13.24 ; p<0.01\right.$; Fig. $6 c)$, and posterior $\left(F_{(2,14)}=16.49 ; p<0.001\right.$; Fig. $\left.6 \mathrm{~d}\right)$.

Bonferroni comparisons indicated a significantly lower number of GPER-positive cells during the diestrus phase compared to males in the whole nucleus and in its middle and posterior regions $(p<0.001, p<0.01$, and $p<$ 0.0001 , respectively; Fig. $6 c, d)$. In addition, in the same portions of the supraoptic nucleus, a significantly higher number of GPER-immunoreactive cells was detected in estrus compared to diestrus $(p>0.001$ in the whole nucleus, $p<0.01$ in the middle portion, and $p<0.05$ in the posterior portion; Fig. $6 \mathrm{c}, \mathrm{d}$ ). No significant differences were detected with the post hoc analysis in the anterior part of the nucleus (Fig. 6b).

Representative microphotographs of GPER immunoreactivity in the supraoptic nucleus of a male rat and a female rat in estrus are shown in Figure 6e and f, respectively.

Hypothalamic GPER Distribution

\section{GPER Immunostaining in the Ventromedial Hypothalamus}

In contrast to the other hypothalamic nuclei analyzed in the present study, no sex differences in the number of GPER-immunoreactive cells were detected in the ventromedial hypothalamus. However, differences between females in estrus and diestrus were observed. ANOVA revealed a significant difference among experimental groups in the number of GPER-immunoreactive cells in the whole nucleus $\left(F_{(2,12)}=13.06\right.$; $p<0.05$; Fig. $\left.7 \mathrm{a}\right)$ that was also detected in its dorsomedial $\left(F_{(2,12)}=9.733 ; p<\right.$ 0.05 ; Fig. $7 b)$, central $\left(F_{(2,12)}=5.499 ; p<0.05\right.$; Fig. $\left.7 c\right)$, and ventrolateral $\left(F_{(2,12)}=4.442 ; p<0.05\right.$; Fig. $\left.7 \mathrm{~d}\right)$ subdivisions.

Post hoc analysis revealed a significantly lower number of GPER-immunoreactive cells in females in estrus compared to diestrous females in the whole nucleus $(p<$ $0.01)$ and in its dorsomedial $(p<0.01)$ and central $(p<$ 0.05 ) subdivisions (Fig. $7 \mathrm{~b}, \mathrm{c}$ ). In addition, the dorsomedial portion of the ventromedial hypothalamus showed a higher number of GPER-immunoreactive cells compared to the central $(p<0.001)$ and ventrolateral $(p<0.001)$ portions of the nucleus in both males and diestrous females and compared to the central portion $(p<0.05)$ in estrous females.

Representative microphotographs of GPER immunoreactivity in the ventromedial hypothalamus of a male rat and a female rat in estrus are shown in Figure $7 \mathrm{e}$ and $\mathrm{f}$, respectively.

\section{Colocalization of GPER and NeuN Immunoreactivity}

Representative examples of GPER colocalization with neuronal (NeuN), astroglial (GFAP), and oligodendroglial (CC1) cell markers are shown in Figure 8.

The proportion of cells immunoreactive for the neuronal marker $\mathrm{NeuN}+$ that were also immunoreactive for GPER (GPER+/NeuN+) was assessed (Fig. 9). ANOVA 


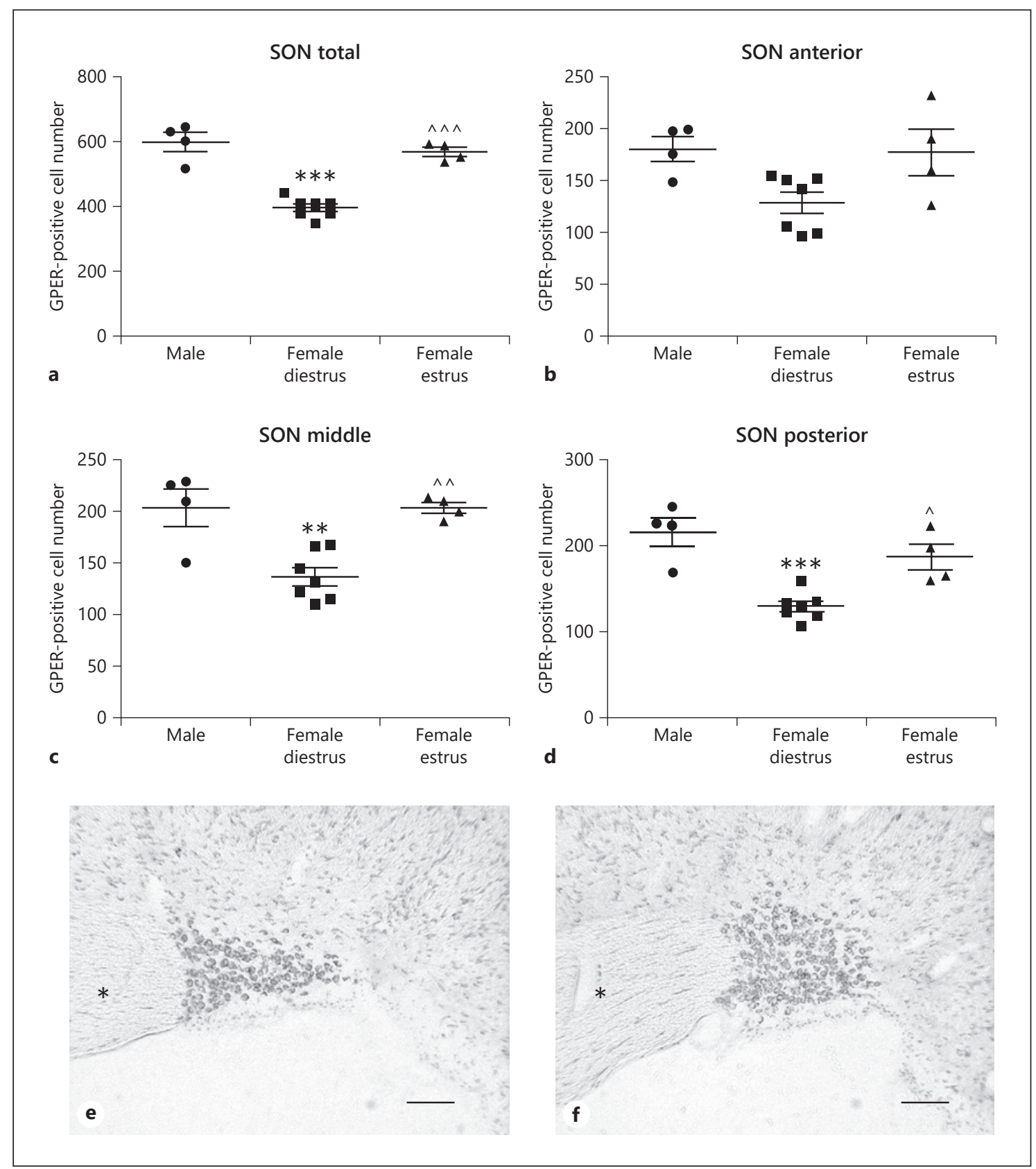

Fig. 6. Number of GPER-immunoreactive cells in the supraoptic nucleus (SON) of male $(n=4)$, diestrous female $(n=7)$, and estrous female $(n=4)$ rats. a SON as a whole. $\mathbf{b}$ Anterior portion of the SON. c Middle portion of the SON. d Posterior portion of the SON. Data are presented as mean \pm SEM. ${ }^{* *}, * * *$ Significant differences $\left({ }^{* *} p<0.01,{ }^{* * *} p<0.001\right)$ versus male values. $\wedge, \wedge \wedge, \wedge \wedge \wedge$ Significant differences $(\wedge p<0.05, \wedge \wedge p<0.01, \wedge \wedge \wedge p<0.001)$ versus females in diestrus. e Representative microphotograph of GPER immunoreactivity in the SON of a male rat. $\mathbf{f}$ Representative microphotograph of GPER immunoreactivity in the SON of a female rat in estrus. Asterisks denote optic chiasma. Scale bars, $100 \mu \mathrm{m}$. GPER, $\mathrm{G}$ protein-coupled estrogen receptor 1 . revealed significant differences between the experimental groups in the proportion of GPER+/NeuN+ cells in the arcuate nucleus $\left(F_{(2,8)}=6.467 ; p<0.05\right.$; Fig. 9a), lateral hypothalamus $\left(F_{(2,8)}=13.29 ; p<0.01\right.$; Fig. $\left.9 \mathrm{~b}\right)$, paraven- tricular nucleus $\left(F_{(2,8)}=31.74 ; p<0.001\right.$; Fig. $\left.9 \mathrm{c}\right)$, and ventromedial hypothalamus $\left(F_{(2,8)}=9.055 ; p<0.05\right.$; Fig. $\left.9 \mathrm{e}\right)$, but not in the supraoptic nucleus $\left(F_{(2,8)}=1.064 ; p=0.402\right.$; Fig. 9d). 


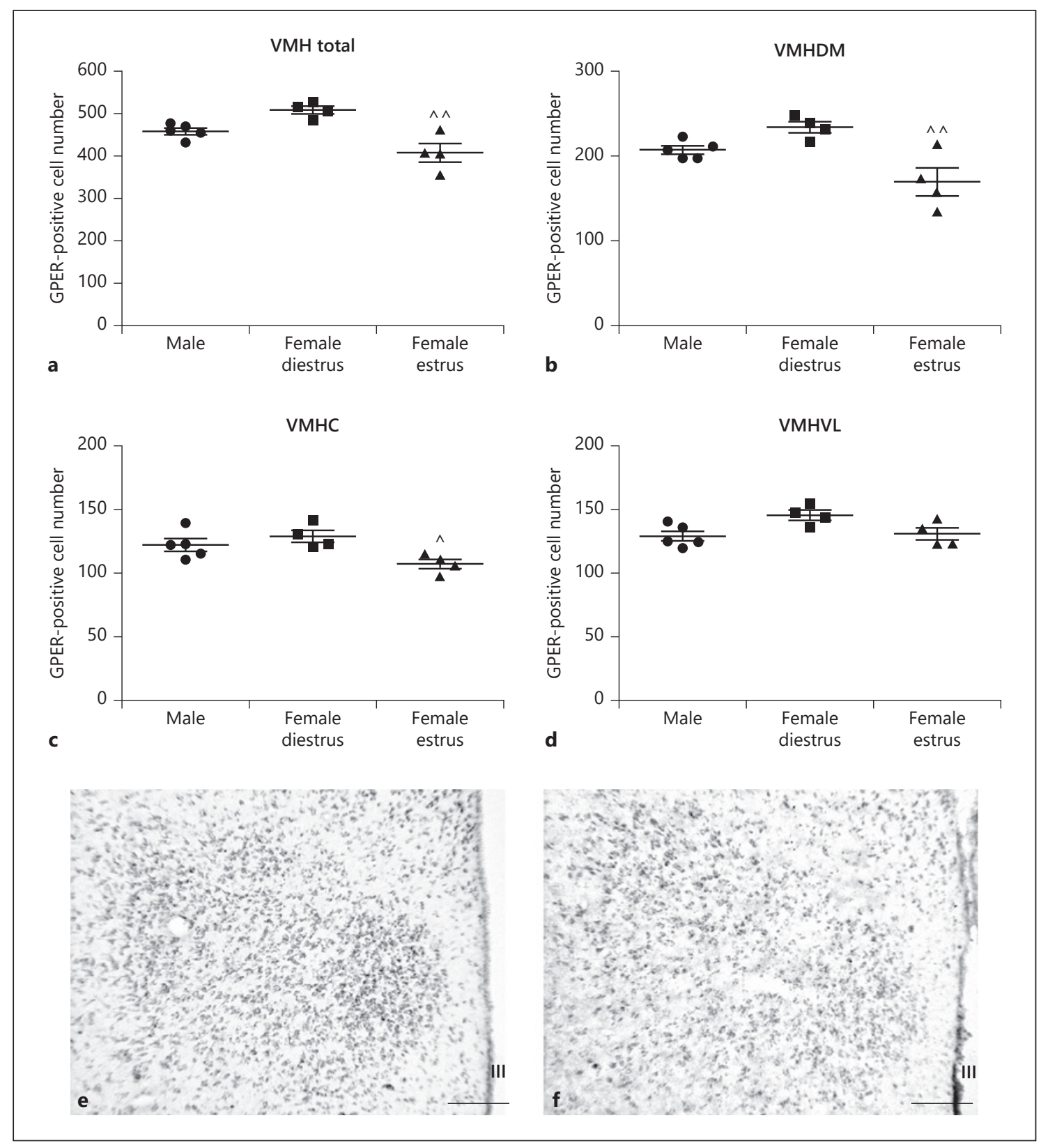

Fig. 7. Number of GPER-immunoreactive cells in the ventromedial hypothalamic nucleus $(\mathrm{VMH})$ of male $(n=5)$, diestrous female $(n=4)$, and estrous female $(n=4)$ rats. a Number of GPERimmunoreactive cells in the whole VMH. b Number of GPERimmunoreactive cells in the dorsomedial portion (VMHDM) of the VMH. c Number of GPER-immunoreactive cells in the central portion (VMHC) of the VMH. d Number of GPER-immunoreac-

Females in estrus showed a higher proportion of GPER+/NeuN+ cells compared to male animals $(p<$ 0.01 ) in the arcuate nucleus (Fig. 9a) and the lateral hypothalamus (Fig. 9b), and to females in diestrus $(p<0.05)$ in tive cells in the ventrolateral portion (VMHVL) of the VMH. Data are presented as mean \pm SEM. $\wedge \wedge \wedge \wedge$ Significant differences $(\wedge p<$ $0.05, \wedge \wedge p<0.01$ ) versus females in diestrus. e Representative microphotograph of GPER immunoreactivity in the VMH of a male rat. $\mathbf{f}$ Representative microphotograph of GPER immunoreactivity in the VMH of a female rat in estrus. Scale bars, $100 \mu \mathrm{m}$. GPER, $\mathrm{G}$ protein-coupled estrogen receptor 1; III, third ventricle.

the lateral hypothalamus (Fig. 9b). In contrast, the paraventricular nucleus (Fig. 9c) and the ventromedial hypothalamus (Fig. 9e) displayed a higher proportion of GPER+/NeuN+ cells in diestrous females than in the oth- 

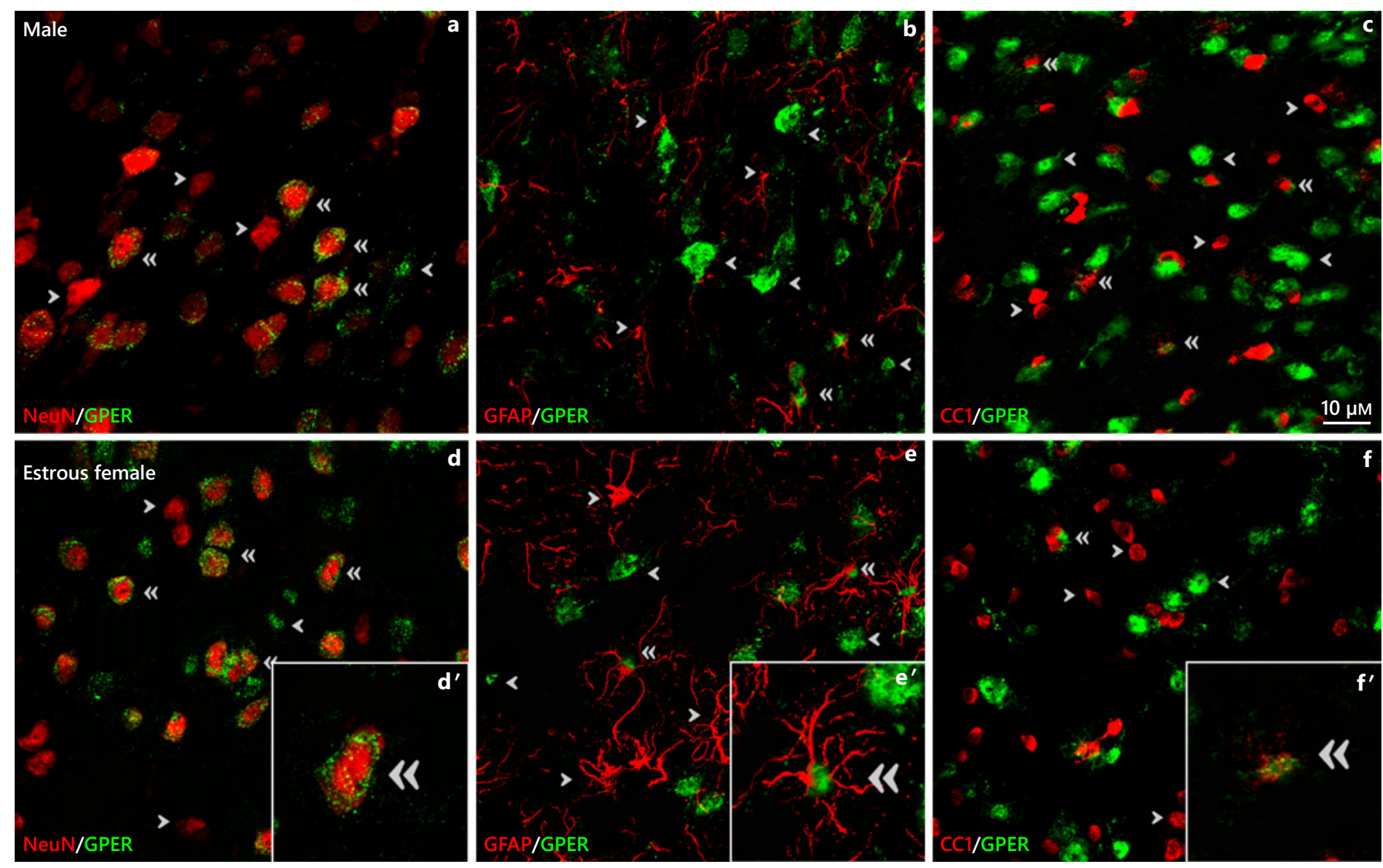

Fig. 8. Representative examples of GPER colocalization with neuronal (NeuN) (a, d), astroglial (GFAP) (b, e), and oligodendroglial (CC1) (c, f) cell markers in the arcuate nucleus of the rat hypothalamus of male $(\mathbf{a}-\mathbf{c})$ and estrous female $(\mathbf{d}-\mathbf{f})$ rats. Single arrow-

heads point to representative single-labeled cells. Double arrowheads point to representative double-labeled cells. Insets show examples of double-labeled cells at high magnification. Scale bar, $10 \mu \mathrm{m}$. GPER, G protein-coupled estrogen receptor 1.

er two experimental groups $(p<0.05$ and $p<0.001$, respectively). No significant differences were detected in the proportion of GPER+/NeuN+ cells between experimental groups in the supraoptic nucleus (Fig. 9d).

\section{Colocalization of GPER and GFAP Immunoreactivity}

GPER immunoreactivity was also colocalized with the astroglial marker GFAP, and the proportion of GFAP+ cells that were also immunoreactive for GPER (GPER+/ GFAP+) was assessed (Fig. 10). ANOVA revealed significant differences in the proportion of GPER+/GFAP+ cells between experimental groups in the arcuate nucleus $\left(F_{(2,8)}=74.16 ; p<0.001\right.$; Fig. 10a), lateral hypothalamus $\left(F_{(2,8)}=8.869 ; p<0.05\right.$; Fig. 10b), and ventromedial hypothalamus $\left(F_{(2,8)}=24.32 ; p<0.01\right.$; Fig. $\left.10 \mathrm{c}\right)$, but not in the paraventricular nucleus $\left(F_{(2,8)}=2.016 ; p=0.213\right.$; Fig. $10 \mathrm{~d})$ or the supraoptic nucleus $\left(F_{(2,8)}=0.076 ; p=\right.$ 0.927; Fig. 10e). A higher proportion of GPER+/GFAP+ cells in estrous females compared to males was detected in the arcuate nucleus ( $p<0.001$; Fig. 10a), lateral hypothalamus ( $p<0.05$; Fig. 10b), and the ventromedial hypothalamus $(p<0.01$; Fig. 10c).

\section{Colocalization of GPER and CC1 Immunoreactivity}

Finally, GPER immunoreactivity was colocalized with the oligodendrocyte marker CC1. The proportion of CC1 cells that were also immunoreactive for GPER (GPER+/ $\mathrm{CC} 1+$ ) was assessed (Fig. 11). ANOVA revealed significant differences in the proportion of GPER+/CC1+ cells between experimental groups in the arcuate nucleus $\left(F_{(2,8)}=21.51 ; p<0.01\right.$; Fig. 11a) and the paraventricular nucleus $\left(F_{(2,8)}=9.374 ; p<0.05\right.$; Fig. 11d), but not in the lateral hypothalamus $\left(F_{(2,8)}=3.400 ; p=0.103\right.$; Fig. 11b), ventromedial hypothalamus $\left(F_{(2,8)}=5.062 ; p=0.051\right.$; Fig. 11c), or supraoptic nucleus $\left(F_{(2,8)}=2.016 ; p=0.213\right.$; Fig. 11e). Post hoc analysis showed a decreased propor- 


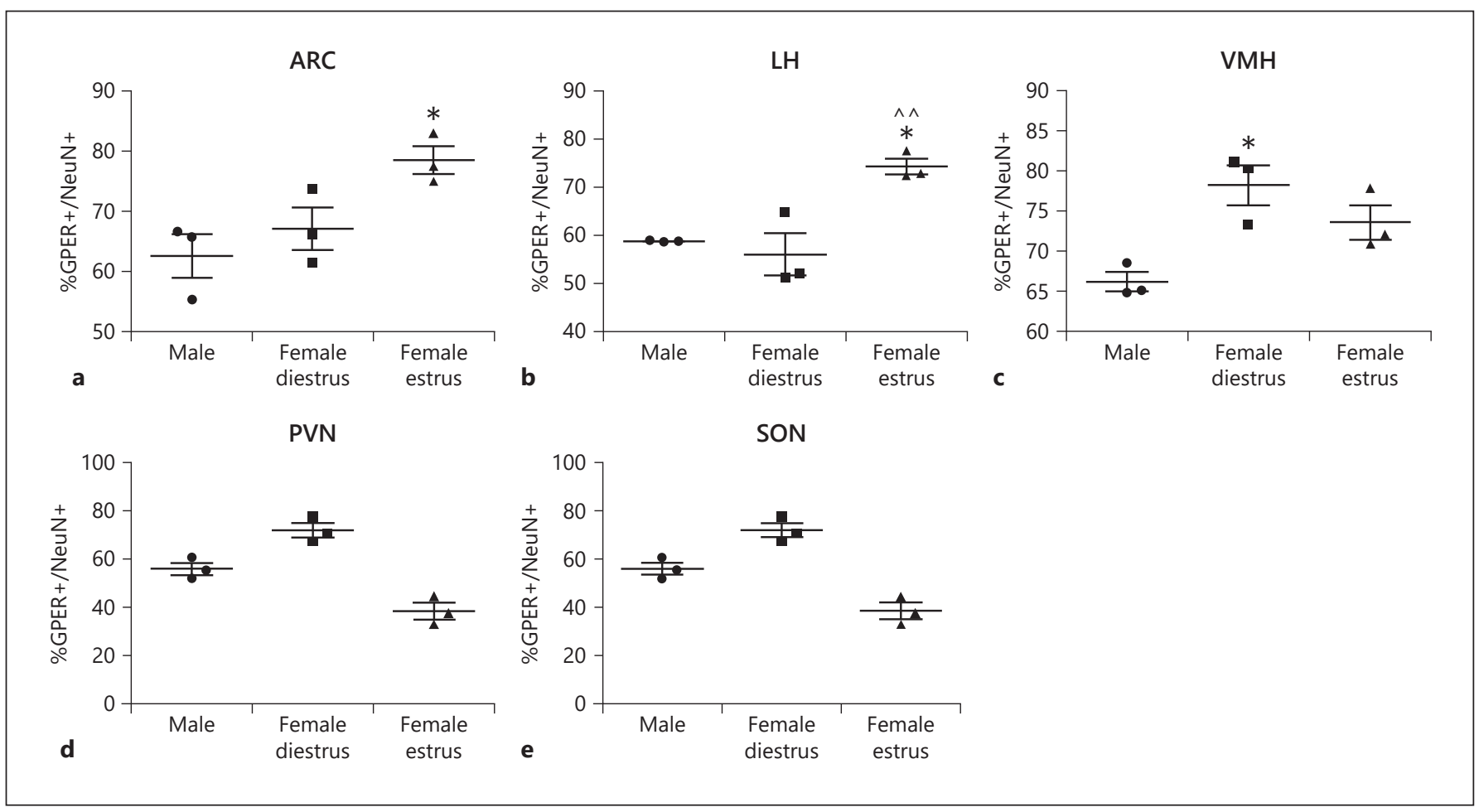

Fig. 9. Proportion of NeuN-immunoreactive neurons that were also immunoreactive for GPER in the hypothalamus of male $(n=$ $3)$, diestrous female $(n=3)$, and estrous female $(n=3)$ rats. a Arcuate nucleus (ARC). b Lateral hypothalamus (LH). c Ventromedial hypothalamus (VMH). d Paraventricular nucleus (PVN).

tion of GPER+/CC1+ cells in estrous and diestrous female rats compared to male animals $(p<0.01)$ in the arcuate nucleus (Fig. 11a), whereas a higher proportion of GPER+/CC1+ cells was detected in estrous females compared to males $(p<0.05)$ in the paraventricular nucleus (Fig. 11d).

\section{Discussion}

Our findings confirm earlier observations of GPER immunoreactivity in the rat hypothalamus [27, 30, 3336]. In addition, in our study we assessed the identity of the cellular types showing GPER immunoreactivity using NeuN, GFAP, and CC1 as specific markers for neurons, astrocytes, and oligodendrocytes, respectively [51-53]. In agreement with previous descriptions in other brain regions [2, 4-9], we observed GPER immunoreactivity in neurons, astrocytes, and oligodendrocytes in the rat hypothalamus. Furthermore, we detected sex and regional differences and changes during the estrous cycle in the e Supraoptic nucleus $(\mathrm{SON})$. Data are presented as mean \pm SEM. * Significant difference $(p<0.05)$ versus male values. $\wedge \wedge$ Significant difference $(p<0.01)$ versus females in diestrus. GPER, G protein-coupled estrogen receptor 1 .

total number of GPER-immunoreactive cells and in the proportion of neurons, astrocytes, and oligodendrocytes that were GPER-immunoreactive.

The existence of sex differences in the number of GPER-immunoreactive cells in the hypothalamus is in agreement with the observation of a higher GPER mRNA expression in this brain region in 60-day-old male hamsters compared to females of the same age [38]. However, our study in rats showed that sex differences in GPER immunoreactivity depend on the hypothalamic region considered. Thus, female rats showed higher numbers of GPER-immunoreactive cells than males in the arcuate nucleus, the lateral hypothalamus, and the supraoptic nucleus. In contrast, males had higher numbers of GPERimmunoreactive cells in the paraventricular nucleus. The possible role of gonadal hormones in the generation of these sex differences remains to be established, although it is known that GPER is regulated by androgens, estradiol, and progesterone in several cellular systems [57-60].

Our findings, showing sex differences in the distribution of hypothalamic GPER immunoreactivity, suggest 


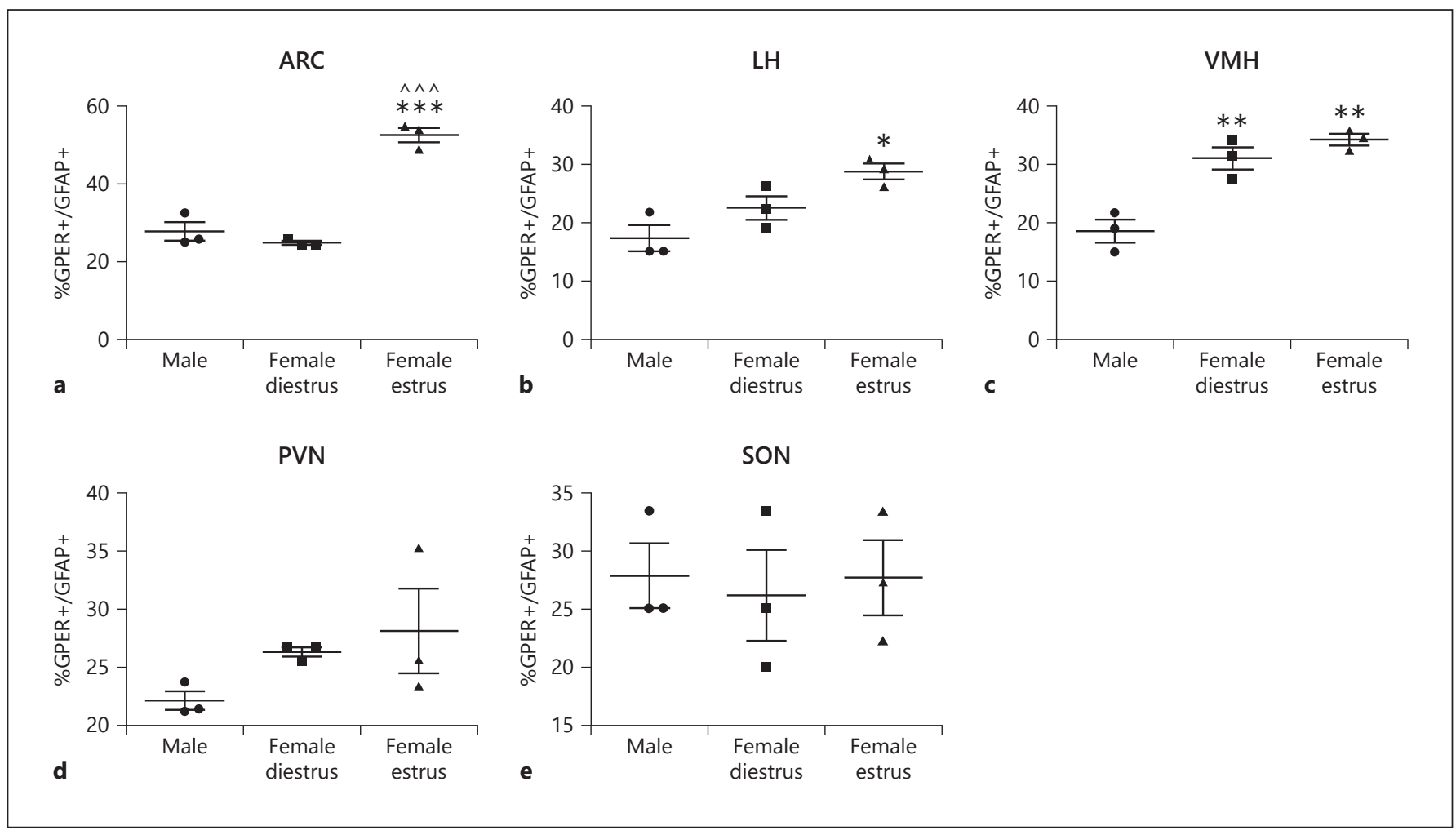

Fig. 10. Proportion of GFAP-immunoreactive astrocytes that were also immunoreactive for GPER in the hypothalamus of male $(n=$ $3)$, diestrous female $(n=3)$, and estrous female $(n=3)$ rats. a Arcuate nucleus (ARC). b Lateral hypothalamus (LH). c Ventromedial hypothalamus (VMH). d Paraventricular nucleus (PVN).

that estrogenic regulation of hypothalamic function through GPER may be different in males and in females. Previous studies in mice have implicated GPER in sex differences in stress and anxiety [61], in the neurological deficits and brain infarct volume after stroke [62], and in the metabolic response and cardiac function after obesity induced by high-fat diet [63]. In this latter case, a possible involvement of hypothalamic GPER cannot be ruled out, although the study was based on a mouse GPER knockout model in which the GPER deletion affected all tissues. Concerning the hypothalamus, it is known that GPER is involved in the estrogenic regulation of the number of arginine-vasopressin-immunoreactive neurons in the supraoptic and paraventricular nucleus of female rats [32]. Furthermore, the GPER-selective agonist G1 decreases ERK immunoreactivity and the number of NADPH diaphorase-positive cells in the supraoptic and paraventricular hypothalamic nuclei in female rats [31]. However, it is unknown whether these effects of GPER observed in females are different in males. In contrast, there is evi- e Supraoptic nucleus (SON). Data are presented as mean \pm SEM. $*, * *, * * *$ Significant differences $\left({ }^{*} p<0.05,{ }^{* *} p<0.01,{ }^{* * *} p<0.001\right)$ versus male values. $\wedge \wedge \wedge$ Significant difference $(p<0.001)$ versus females in diestrus. GPER, G protein-coupled estrogen receptor 1.

dence that GPER is involved in lordosis [27-30], a sex dimorphic behavioral response controlled by the hypothalamus. Indeed, estradiol facilitates lordosis by acting on GPER in the arcuate nucleus $[27,29,30]$, which shows higher GPER immunoreactivity in females, as determined in the present study.

Sex differences were not only observed in the number of GPER-immunoreactive cells but also in the proportion of neurons, astrocytes, and oligodendrocytes that were GPER-immunoreactive. Thus, males show a lower proportion of neurons immunoreactive for GPER in the arcuate nucleus and the lateral hypothalamus, compared to females in estrus, and in the paraventricular nucleus and the ventromedial hypothalamus, compared to diestrous females. These sex differences in GPER distribution may contribute to the well-characterized differences in the functional and structural parameters of hypothalamic neurons [64-67]. In addition, sex differences in GPER immunoreactivity were also detected in glial cells. Compared to males, there is a higher proportion of GPER- 


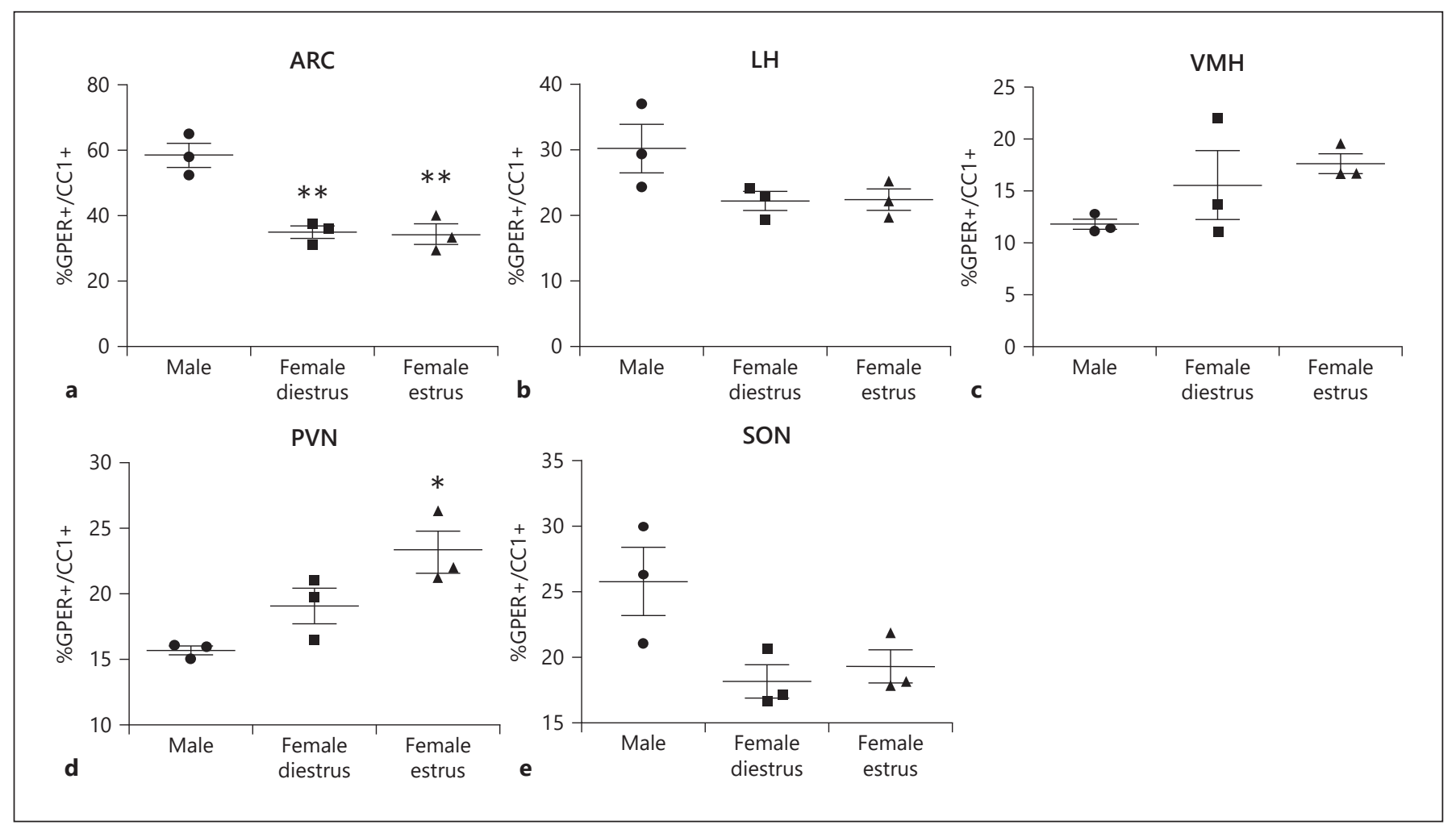

Fig. 11. Proportion of CC1-immunoreactive oligodendrocytes that were also immunoreactive for GPER in the hypothalamus of male $(n=3)$, diestrous female $(n=3)$, and estrous female $(n=3)$ rats. a Arcuate nucleus (ARC). b Lateral hypothalamus (LH). c Ventromedial hypothalamus (VMH). d Paraventricular nucleus (PVN). e Supraoptic nucleus (SON). Data are presented as mean \pm SEM. ${ }^{*}, * *$ Significant differences $\left({ }^{*} p<0.05,{ }^{* *} p<0.01\right)$ versus male values. GPER, G protein-coupled estrogen receptor 1 . immunoreactive astrocytes in the arcuate nucleus, lateral hypothalamus, and ventromedial hypothalamus of estrous females. Furthermore, in the arcuate nucleus the proportion of GPER-immunoreactive oligodendrocytes is higher in males than in estrous and diestrous females. In contrast, the proportion of GPER-immunoreactive oligodendrocytes in the paraventricular nucleus is higher in estrous females than in males. Sex differences in GPER expression in astrocytes and oligodendrocytes may contribute to the reported functional dimorphic phenotype of these cells in male and female animals $[68,69]$. In particular, accumulating evidence indicates that astrocytes participate in the generation of sex differences in hypothalamic function [70-74]. Our findings suggest that GPER may participate in the estrogenic modulation of these glial effects.

Our present findings also indicate that GPER immunoreactivity fluctuates during the estrous cycle in the hypothalamus. Thus, females in estrus have a higher number of GPER-immunoreactive cells than diestrous females in the anterior part of the arcuate nucleus, the anterior part of the lateral hypothalamus, and in the supraoptic nucleus. In contrast, the paraventricular nucleus and the ventromedial hypothalamus have a higher number of GPER-immunoreactive cells in diestrus than in estrus. These fluctuations in the number of GPER-immunoreactive cells during the estrous cycle are accompanied by significant changes in the proportion of GPER-immunoreactive neurons. Thus, estrous females have a higher proportion of GPER-immunoreactive neurons than diestrous females in the arcuate nucleus and the lateral hypothalamus. In contrast, females in diestrus have a higher proportion of GPER-immunoreactive neurons in the ventromedial hypothalamus and the paraventricular nucleus. However, the proportion of GPER-immunoreactive astrocytes and oligodendrocytes does not show significant changes during the estrous cycle in the hypothalamic regions analyzed.

Our present observations in the hypothalamus extend the results of previous studies showing that GPER mRNA levels fluctuate during the estrous cycle in other rat brain regions, such as the nucleus of the solitary tract, the peri- 
aqueductal gray, and the ventrolateral medulla [40]. Changes in GPER immunoreactivity during the estrous cycle may reflect an estrogenic regulation of GPER trough other estrogen receptor variants or by an autoregulatory mechanism, as has been suggested by other studies [57, $60]$. In this regard, it should be considered that we analyzed two estrous cycle phases, estrus and diestrus 2, that diol. Thus, the estrous phase corresponds to the day after the peak of estradiol in proestrus, when most transcriptional, functional, and behavioral effects of the hormone are manifested, in contrast to diestrus 2 (i.e., $72 \mathrm{~h}$ after the peak of estradiol in proestrus). It is important to note that with this choice we favored the detection of possible transcriptional effects of estradiol on GPER expression or localization over rapid nongenomic effects of the hormonal peak in proestrus, which could also have been interesting to analyze. Furthermore, fluctuation of progesterone levels during the estrous cycle may also influence GPER expression, since progesterone A receptor transfection has been shown to decrease GPER expression in Ishikawa cells [75] and the pituitary expression of GPER in adult female rats is decreased $24 \mathrm{~h}$ after the administration of progesterone in vivo [59].

Phasic changes in GPER expression in the hypothalamus may contribute to the fluctuation during the estrous cycle in the expression of estrogen-regulated hypothalamic proteins, such as oxytocin and vasopressin [76], kisspeptin [77], neuropeptide Y [78], orexin [79], nitric oxide synthase [80], or growth hormone and prolactin, among others [81]. Changes in GPER immunoreactivity in the hypothalamus may also participate in the estrogenic regulation of neuroglial plasticity during the estrous cycle [82-87] and in the preparation for estrogenpositive feedback, luteinizing hormone surge, ovulation, and sexual receptivity in females [27, 29, 88].

In summary, our findings showing that GPER immunoreactivity is widely distributed in the hypothalamus, presents sex differences, and fluctuates during the estrous cycle suggest that this form of estrogen receptor may be involved in the hormonal regulation of numerous hypothalamic functions mediated by neurons and glial cells.

\section{Statement of Ethics}

The experiments performed in this study were in accordance with European Directive 2010/63/EU and in compliance with the Spanish Royal Decree 53/2013 on the protection of animals used for research and other scientific purposes. The protocol was aprepresent two extremes in the biological effects of estra-

proved by the bioethics committee of the Universidad Nacional de Educación a Distancia. Animals were handled in accordance with the guidelines published in the NIH Guide for the Care and Use of Laboratory Animals, the principles presented in the Guidelines for the Use of Animals in Neuroscience Research by the Society for Neuroscience, and following the European Union (2010/63/UE) and the Spanish legislation (L6/2013; RD53/2013). The experimental procedures were approved by our Institutional Animal Use and Care Committee (Universidad Nacional de Educación a Distancia, Madrid). Special care was taken to minimize animal suffering and to reduce the number of animals used to the minimum necessary.

\section{Conflict of Interest Statement}

The authors have no conflicts of interest to declare.

\section{Funding Sources}

This study was supported by the Ministero dell'Istruzione, dell'Università e della Ricerca, Italy (MIUR project Dipartimenti di Eccellenza 2018-2022) to the Department of Neuroscience Rita LeviMontalcini, Agencia Estatal de Investigación, Spain (BFU201782754-R), Centro de Investigación Biomédica en Red Fragilidad y Envejecimiento Saludable, Instituto de Salud Carlos III, Madrid and Fondos FEDER. The fellowship of M. Marraudino was generously granted by Prof. G.C. Bergui.

\section{Author Contributions}

D. Grassi, L.M. Garcia-Segura, and P. Collado designed and supervised the experiments. M. Marraudino, D. Grassi, E. Campioli, B. Bonaldo, R. Llorente, B. Carrillo, and H. Pinos performed the experiments. R. Llorente and I. Garate prepared the figures for publication. D. Grassi, M. Marraudino, and L.M. Garcia-Segura wrote the first draft of the manuscript. All authors read and approved the manuscript.

\section{References}

1 Barton M, Filardo EJ, Lolait SJ, Thomas P, Maggiolini M, Prossnitz ER. Twenty years of the $G$ protein-coupled estrogen receptor GPER: historical and personal perspectives. J Steroid Biochem Mol Biol. 2018 Feb;176:415.

2 Hammond R, Nelson D, Gibbs RB. GPR30 co-localizes with cholinergic neurons in the basal forebrain and enhances potassiumstimulated acetylcholine release in the hippocampus. Psychoneuroendocrinology. 2011 Feb;36(2):182-92.

3 Almey A, Filardo EJ, Milner TA, Brake WG. Estrogen receptors are found in glia and at extranuclear neuronal sites in the dorsal striatum of female rats: evidence for cholinergic but not dopaminergic colocalization. Endocrinology. 2012 Nov;153(11):5373-83. 
4 Akama KT, Thompson LI, Milner TA, McEwen BS. Post-synaptic density-95 (PSD95) binding capacity of G-protein-coupled receptor 30 (GPR30), an estrogen receptor that can be identified in hippocampal dendritic spines. J Biol Chem. 2013 Mar;288(9):6438-50.

5 Waters EM, Thompson LI, Patel P, Gonzales AD, Ye HZ, Filardo EJ, et al. G-protein-coupled estrogen receptor 1 is anatomically positioned to modulate synaptic plasticity in the mouse hippocampus. J Neurosci. 2015 Feb; 35(6):2384-97.

6 Roque C, Mendes-Oliveira J, Baltazar G. G protein-coupled estrogen receptor activates cell type-specific signaling pathways in cortical cultures: relevance to the selective loss of astrocytes. J Neurochem. 2019 Apr;149(1): 27-40.

7 Almey A, Cannell E, Bertram K, Filardo E, Milner TA, Brake WG. Medial prefrontal cortical estradiol rapidly alters memory system bias in female rats: ultrastructural analysis reveals membrane-associated estrogen receptors as potential mediators. Endocrinology. 2014 Nov; 155(11):4422-32.

8 Hirahara Y, Matsuda K, Gao W, Arvanitis DN, Kawata M, Boggs JM. The localization and non-genomic function of the membraneassociated estrogen receptor in oligodendrocytes. Glia. 2009 Jan;57(2):153-65.

9 Hirahara Y, Matsuda KI, Yamada H, Saitou A, Morisaki S, Takanami K, et al. G protein-coupled receptor 30 contributes to improved remyelination after cuprizone-induced demyelination. Glia. 2013 Mar;61(3):420-31.

10 Altmann JB, Yan G, Meeks JF, Abood ME, Brailoiu E, Brailoiu GC. G protein-coupled estrogen receptor-mediated effects on cytosolic calcium and nanomechanics in brain microvascular endothelial cells. J Neurochem. 2015 Jun;133(5):629-39.

11 Deliu E, Brailoiu GC, Arterburn JB, Oprea TI, Benamar K, Dun NJ, et al. Mechanisms of G protein-coupled estrogen receptor-mediated spinal nociception. J Pain. 2012 Aug;13(8): 742-54.

12 Brailoiu GC, Arterburn JB, Oprea TI, Chitravanshi VC, Brailoiu E. Bradycardic effects mediated by activation of $\mathrm{G}$ protein-coupled estrogen receptor in rat nucleus ambiguus. Exp Physiol. 2013 Mar;98(3):679-91.

13 Gibbs RB, Nelson D, Hammond R. Role of GPR30 in mediating estradiol effects on acetylcholine release in the hippocampus. Horm Behav. 2014 Jul;66(2):339-45.

14 Kumar A, Bean LA, Rani A, Jackson T, Foster TC. Contribution of estrogen receptor subtypes, ERa, ER $\beta$, and GPER1 in rapid estradiol-mediated enhancement of hippocampal synaptic transmission in mice. Hippocampus. 2015 Dec;25(12):1556-66.

15 Yang R, Zhang B, Chen T, Zhang S, Chen L. Postpartum estrogen withdrawal impairs GABAergic inhibition and LTD induction in basolateral amygdala complex via down-regulation of GPR30. Eur Neuropsychopharmacol. 2017 Aug;27(8):759-72.
$16 \mathrm{Xu} \mathrm{W,} \mathrm{Cao} \mathrm{J,} \mathrm{Zhou} \mathrm{Y,} \mathrm{Wang} \mathrm{L,} \mathrm{Zhu} \mathrm{G.} \mathrm{GPR30}$ activation improves memory and facilitates DHPG-induced LTD in the hippocampal CA3 of middle-aged mice. Neurobiol Learn Mem. 2018 Mar;149:10-9.

17 Ruiz-Palmero I, Hernando M, Garcia-Segura LM, Arevalo MA. G protein-coupled estrogen receptor is required for the neuritogenic mechanism of $17 \beta$-estradiol in developing hippocampal neurons. Mol Cell Endocrinol. 2013 Jun;372(1-2):105-15.

18 Tang H, Zhang Q, Yang L, Dong Y, Khan M, Yang F, et al. Reprint of "GPR30 mediates estrogen rapid signaling and neuroprotection." Mol Cell Endocrinol. 2014 May;389(1-2):928.

19 Cheng Q, Meng J, Wang XS, Kang WB, Tian Z, Zhang K, et al. G-1 exerts neuroprotective effects through $\mathrm{G}$ protein-coupled estrogen receptor 1 following spinal cord injury in mice. Biosci Rep. 2016 Aug;36(4):e00373-83.

20 Evans NJ, Bayliss AL, Reale V, Evans PD. Characterisation of signalling by the endogenous GPER1 (GPR30) receptor in an embryonic mouse hippocampal cell line (mHippoE-18). PLoSOne.2016Mar;11(3):e0152138.

21 Wang XS, Yue J, Hu LN, Tian Z, Zhang K, Yang $L$, et al. Activation of $G$ protein-coupled receptor 30 protects neurons by regulating autophagy in astrocytes. Glia. 2020 Jan;68(1): 27-43.

22 Lee E, Sidoryk-Wêgrzynowicz M, Wang N, Webb A, Son DS, Lee K, et al. GPR30 regulates glutamate transporter GLT-1 expression in rat primary astrocytes. J Biol Chem. 2012 Aug;287(32):26817-28.

23 Gonzalez GA, Hofer MP, Syed YA, Amaral AI, Rundle J, Rahman S, et al. Tamoxifen accelerates the repair of demyelinated lesions in the central nervous system. Sci Rep. 2016 Aug;6(1):31599.

24 Kim J, Szinte JS, Boulware MI, Frick KM. $17 \beta$-Estradiol and Agonism of G-proteinCoupled Estrogen Receptor Enhance Hippocampal Memory via Different Cell-Signaling Mechanisms. J Neurosci. 2016 Mar;36(11): 3309-21.

25 Paletta P, Sheppard PA, Matta R, Ervin KS, Choleris E. Rapid effects of estrogens on short-term memory: possible mechanisms. Horm Behav. 2018 Aug;104:88-99.

26 Kwon O, Kang ES, Kim I, Shin S, Kim M, Kwon S, et al. GPR30 mediates anorectic estrogen-induced STAT3 signaling in the hypothalamus. Metabolism. 2014 Nov;63(11): 1455-61.

27 Tominna R, Chokr S, Feri M, Chuon T, Sinchak K. Plasma membrane G protein-coupled estrogen receptor 1 (GPER) mediates rapid estradiol facilitation of sexual receptivity through the orphanin-FQ-ORL-1 system in estradiol primed female rats. Horm Behav. 2019 Jun;112:89-99.

28 Anchan D, Gafur A, Sano K, Ogawa S, Vasudevan N. Activation of the GPR30 receptor promotes lordosis in female mice. Neuroendocrinology. 2014;100(1):71-80.
29 Long N, Serey C, Sinchak K. 17 $\beta$-estradiol rapidly facilitates lordosis through $\mathrm{G}$ proteincoupled estrogen receptor 1 (GPER) via deactivation of medial preoptic nucleus $\mu$-opioid receptors in estradiol primed female rats. Horm Behav. 2014 Sep;66(4):663-6.

30 Long N, Long B, Mana A, Le D, Nguyen L, Chokr S, et al. Tamoxifen and ICI 182,780 activate hypothalamic $\mathrm{G}$ protein-coupled estrogen receptor 1 to rapidly facilitate lordosis in female rats. Horm Behav. 2017 Mar;89:98103.

31 Grassi D, Lagunas N, Pinos H, Panzica G, Garcia-Segura LM, Collado P. NADPH-Diaphorase Colocalizes with GPER and Is Modulated by the GPER Agonist G1 in the Supraoptic and Paraventricular Nuclei of Ovariectomized Female Rats. Neuroendocrinology. 2017;104(1):94-104.

32 Lagunas N, Marraudino M, de Amorim M, Pinos H, Collado P, Panzica G, et al. Estrogen receptor beta and $G$ protein-coupled estrogen receptor 1 are involved in the acute estrogenic regulation of arginine-vasopressin immunoreactive levels in the supraoptic and paraventricular hypothalamic nuclei of female rats. Brain Res. 2019 Jun;1712:93-100.

33 Brailoiu E, Dun SL, Brailoiu GC, Mizuo K, Sklar LA, Oprea TI, et al. Distribution and characterization of estrogen receptor $\mathrm{G}$ protein-coupled receptor 30 in the rat central nervous system. J Endocrinol. 2007 May;193(2):311-21.

34 Sakamoto H, Matsuda K, Hosokawa K, Nishi M, Morris JF, Prossnitz ER, et al. Expression of $G$ protein-coupled receptor-30, a $G$ protein-coupled membrane estrogen receptor, in oxytocin neurons of the rat paraventricular and supraoptic nuclei. Endocrinology. 2007 Dec;148(12):5842-50.

35 Uddin MM, Mahmood AS, Ibrahim MM, Briski KP. Sex-dimorphic estrogen receptor regulation of ventromedial hypothalamic nucleus glucoregulatory neuron adrenergic receptor expression in hypoglycemic male and female rats. Brain Res. 2019 Oct;1720:146311.

36 Wang YX, Zhu L, Li LX, Xu HN, Wang HG, An D, et al. Postnatal expression patterns of estrogen receptor subtypes and choline acetyltransferase in different regions of the Papez circuit. Dev Neurosci. 2019;41(3-4):203-11.

37 Hazell GG, Yao ST, Roper JA, Prossnitz ER, O'Carroll AM, Lolait SJ. Localisation of GPR30, a novel G protein-coupled oestrogen receptor, suggests multiple functions in rodent brain and peripheral tissues. J Endocrinol. 2009 Aug;202(2):223-36.

38 Canonaco M, Giusi G, Madeo A, Facciolo RM, Lappano R, Canonaco A, et al. A sexually dimorphic distribution pattern of the novel estrogen receptor G-protein-coupled receptor 30 in some brain areas of the hamster. J Endocrinol. 2008 Jan;196(1):131-8. 
39 Naugle MM, Nguyen LT, Merceron TK, Filardo E, Janssen WG, Morrison JH, et al. Gprotein coupled estrogen receptor, estrogen receptor $\alpha$, and progesterone receptor immunohistochemistry in the hypothalamus of aging female rhesus macaques given long-term estradiol treatment. J Exp Zool A Ecol Genet Physiol. 2014 Aug;321(7):399-414.

40 Spary EJ, Chapman SE, Sinfield JK, Maqbool A, Kaye J, Batten TF. Novel G protein-coupled oestrogen receptor GPR30 shows changes in mRNA expression in the rat brain over the oestrous cycle. Neurosignals. 2013;21(12):14-27.

41 Marcondes FK, Bianchi FJ, Tanno AP. Determination of the estrous cycle phases of rats: some helpful considerations. Braz J Biol. 2002 Nov;62(4A):609-14.

42 Hubscher $\mathrm{CH}$, Brooks DL, Johnson JR. A quantitative method for assessing stages of the rat estrous cycle. Biotech Histochem. 2005 Mar-Apr;80(2):79-87.

43 Paxinos G, Watson C. The rat brain in stereotaxic coordinates. 4th ed. New York: Academic Press; 1998.

44 Watson RE Jr, Wiegand SJ, Clough RW, Hoffman GE. Use of cryoprotectant to maintain long-term peptide immunoreactivity and tissue morphology. Peptides. 1986 Jan-Feb; 7(1):155-9.

45 Zhao J, Bian C, Liu M, Zhao Y, Sun T, Xing F, et al. Orchiectomy and letrozole differentially regulate synaptic plasticity and spatial memory in a manner that is mediated by SRC- 1 in the hippocampus of male mice. J Steroid Biochem Mol Biol. 2018 Apr;178:354-68.

46 Meseke M, Neumüller F, Brunne B, Li X, Anstötz M, Pohlkamp T, et al. Distal dendritic enrichment of HCN1 channels in hippocampal CA1 is promoted by estrogen, but does not require reelin. eNeuro. 2018 Oct;5(5): ENEURO.0258-18.2018.

47 Wu Y, Feng D, Lin J, Qu Y, He S, Wang Y, et al. Downregulation of G-protein-coupled receptor 30 in the hippocampus attenuates the neuroprotection of estrogen in the critical period hypothesis. Mol Med Rep. 2018 Apr; 17(4):5716-25.

48 Zhang Y, Xiao X, Zhang XM, Zhao ZQ, Zhang YQ. Estrogen facilitates spinal cord synaptic transmission via membrane-bound estrogen receptors: implications for pain hypersensitivity. J Biol Chem. 2012 Sep;287(40):3326881.

49 Klenke U, Constantin S, Wray S. BPA Directly Decreases GnRH Neuronal Activity via Noncanonical Pathway. Endocrinology. 2016 May;157(5):1980-90.

50 Wang W, Le AA, Hou B, Lauterborn JC, Cox CD, Levin ER, et al. Memory-Related Synaptic Plasticity Is Sexually Dimorphic in Rodent Hippocampus. J Neurosci. 2018 Sep;38(37): 7935-51.

51 Gusel'nikova VV, Korzhevskiy DE. NeuN as a neuronal nuclear antigen and neuron differentiation marker. Acta Naturae. 2015 AprJun;7(2):42-7.
52 Middeldorp J, Hol EM. GFAP in health and disease. Prog Neurobiol. 2011 Mar;93(3): 421-43.

53 Bin JM, Harris SN, Kennedy TE. The oligodendrocyte-specific antibody "CC1" binds Quaking 7. J Neurochem. 2016 Oct;139(2): 181-6.

54 Dent MA, Segura-Anaya E, Alva-Medina J, Aranda-Anzaldo A. NeuN/Fox-3 is an intrinsic component of the neuronal nuclear matrix. FEBS Lett. 2010 Jul;584(13):2767-71.

55 Armstrong WE, Warach S, Hatton GI, McNeill TH. Subnuclei in the rat hypothalamic paraventricular nucleus: a cytoarchitectural, horseradish peroxidase and immunocytochemical analysis. Neuroscience. 1980; 5(11):1931-58.

56 Grassi D, Lagunas N, Amorim M, Pinos H, Panzica G, Garcia-Segura LM, et al. Role of oestrogen receptors on the modulation of $\mathrm{NADPH}$-diaphorase-positive cell number in supraoptic and paraventricular nuclei of ovariectomised female rats. J Neuroendocrinol. 2013 Mar;25(3):244-50.

57 Cheng SB, Dong J, Pang Y, LaRocca J, Hixon $\mathrm{M}$, Thomas $\mathrm{P}$, et al. Anatomical location and redistribution of $G$ protein-coupled estrogen receptor-1 during the estrus cycle in mouse kidney and specific binding to estrogens but not aldosterone. Mol Cell Endocrinol. 2014 Feb;382(2):950-9.

58 Shen Y, Yang F, Zhang W, Song W, Liu Y, Guan X. The Androgen Receptor Promotes Cellular Proliferation by Suppression of GProtein Coupled Estrogen Receptor Signaling in Triple-Negative Breast Cancer. Cell Physiol Biochem. 2017;43(5):2047-61.

59 Camilletti MA, Abeledo-Machado A, Ferraris J, Pérez PA, Faraoni EY, Pisera D, et al. Role of GPER in the anterior pituitary gland focusing on lactotroph function. J Endocrinol. 2019 Feb;240(2):99-110.

60 Ibrahim MM, Bheemanapally K, Sylvester PW, Briski KP. Sex-specific estrogen regulation of hypothalamic astrocyte estrogen receptor expression and glycogen metabolism in rats. Mol Cell Endocrinol. 2020 Mar;504: 110703.

61 Kastenberger I, Schwarzer C. GPER1 (GPR30) knockout mice display reduced anxiety and altered stress response in a sex and paradigm dependent manner. Horm Behav. 2014 Sep; 66(4):628-36.

62 Broughton BR, Brait VH, Kim HA, Lee S, Chu HX, Gardiner-Mann CV, et al. Sex-dependent effects of $G$ protein-coupled estrogen receptor activity on outcome after ischemic stroke. Stroke. 2014 Mar;45(3):835-41.

63 Meoli L, Isensee J, Zazzu V, Nabzdyk CS, Soewarto D, Witt H, et al. Sex- and age-dependent effects of Gpr30 genetic deletion on the metabolic and cardiovascular profiles of diet-induced obese mice. Gene. 2014 May; 540(2):210-6.
64 Simerly RB. Organization and regulation of sexually dimorphic neuroendocrine pathways. Behav Brain Res. 1998 May;92(2):195203.

65 Flanagan-Cato LM. Sex differences in the neural circuit that mediates female sexual receptivity. Front Neuroendocrinol. 2011 Apr; 32(2):124-36.

66 Yang CF, Chiang MC, Gray DC, Prabhakaran M, Alvarado M, Juntti SA, et al. Sexually dimorphic neurons in the ventromedial hypothalamus govern mating in both sexes and aggression in males. Cell. 2013 May;153(4):896909.

67 Fukushima A, Hagiwara H, Fujioka H, Kimura F, Akema T, Funabashi T. Sex differences in feeding behavior in rats: the relationship with neuronal activation in the hypothalamus. Front Neurosci. 2015 Mar;9:88.

68 Cerghet M, Skoff RP, Swamydas M, Bessert D. Sexual dimorphism in the white matter of rodents. J Neurol Sci. 2009 Nov;286(1-2):7680.

69 Acaz-Fonseca E, Avila-Rodriguez M, GarciaSegura LM, Barreto GE. Regulation of astroglia by gonadal steroid hormones under physiological and pathological conditions. Prog Neurobiol. 2016 Sep;144:5-26.

70 Garcia-Segura LM, Naftolin F, Hutchison JB, Azcoitia I, Chowen JA. Role of astroglia in estrogen regulation of synaptic plasticity and brain repair. J Neurobiol. 1999 Sep;40(4): $574-84$

71 Mong JA, McCarthy MM. Ontogeny of sexually dimorphic astrocytes in the neonatal rat arcuate. Brain Res Dev Brain Res. 2002 Dec; 139(2):151-8.

72 Kuo J, Hamid N, Bondar G, Dewing P, Clarkson J, Micevych P. Sex differences in hypothalamic astrocyte response to estradiol stimulation. Biol Sex Differ. 2010 Nov;1(1):7.

73 Argente-Arizón P, Guerra-Cantera S, GarciaSegura LM, Argente J, Chowen JA. Glial cells and energy balance. J Mol Endocrinol. 2017 Jan;58(1):R59-71.

74 Chowen JA, Argente-Arizón P, Freire-Regatillo A, Argente J. Sex differences in the neuroendocrine control of metabolism and the implication of astrocytes. Front Neuroendocrinol. 2018 Jan;48:3-12.

75 Plante BJ, Lessey BA, Taylor RN, Wang W, Bagchi MK, Yuan L, et al. G protein-coupled estrogen receptor (GPER) expression in nor$\mathrm{mal}$ and abnormal endometrium. Reprod Sci. 2012 Jul;19(7):684-93.

76 Greer ER, Caldwell JD, Johnson MF, Prange AJ Jr, Pedersen CA. Variations in concentration of oxytocin and vasopressin in the paraventricular nucleus of the hypothalamus during the estrous cycle in rats. Life Sci. 1986 Jun; 38(25):2311-8.

77 Marraudino M, Miceli D, Farinetti A, Ponti G, Panzica G, Gotti S. Kisspeptin innervation of the hypothalamic paraventricular nucleus: sexual dimorphism and effect of estrous cycle in female mice. J Anat. 2017 Jun;230(6):77586. 
78 Martini M, Sica M, Gotti S, Eva C, Panzica GC. Effects of estrous cycle and sex on the expression of neuropeptide $\mathrm{Y} Y 1$ receptor in discrete hypothalamic and limbic nuclei of transgenic mice. Peptides. 2011 Jun;32(6):1330-4.

79 Porkka-Heiskanen T, Kalinchuk A, Alanko L, Huhtaniemi I, Stenberg D. Orexin A and B levels in the hypothalamus of female rats: the effects of the estrous cycle and age. Eur J Endocrinol. 2004 May;150(5):737-42.

80 Sica M, Martini M, Viglietti-Panzica C, Panzica G. Estrous cycle influences the expression of neuronal nitric oxide synthase in the hypothalamus and limbic system of female mice. BMC Neurosci. 2009 Jul;10(1):78.

81 DiCarlo LM, Vied C, Nowakowski RS. The stability of the transcriptome during the estrous cycle in four regions of the mouse brain. J Comp Neurol. 2017 Oct;525(15):3360-87.
82 Olmos G, Naftolin F, Perez J, Tranque PA, Garcia-Segura LM. Synaptic remodeling in the rat arcuate nucleus during the estrous cycle. Neuroscience. 1989;32(3):663-7.

83 Garcia-Segura LM, Luquín S, Párducz A, Naftolin F. Gonadal hormone regulation of glial fibrillary acidic protein immunoreactivity and glial ultrastructure in the rat neuroendocrine hypothalamus. Glia. 1994 Jan;10(1):5969.

84 Flanagan-Cato LM. Estrogen-induced remodeling of hypothalamic neural circuitry. Front Neuroendocrinol. 2000 Oct;21(4):30929.

85 Csakvari E, Hoyk Z, Gyenes A, Garcia-Ovejero D, Garcia-Segura LM, Párducz A. Fluctuation of synapse density in the arcuate nucleus during the estrous cycle. Neuroscience. 2007 Feb;144(4):1288-92.
86 Barrera-Ocampo A, Gutierrez-Vargas J, Garcia-Segura LM, Cardona-Gómez GP. Glycogen synthase kinase- $3 \beta / \beta$-catenin signaling in the rat hypothalamus during the estrous $\mathrm{cy}$ cle. J Neurosci Res. 2012 May;90(5):1078-84.

87 González-Burgos I, Velázquez-Zamora DA, González-Tapia D, Cervantes M. A Golgi study of the plasticity of dendritic spines in the hypothalamic ventromedial nucleus during the estrous cycle of female rats. Neuroscience. 2015 Jul;298:74-80.

88 Kuo J, Hamid N, Bondar G, Prossnitz ER, Micevych P. Membrane estrogen receptors stimulate intracellular calcium release and progesterone synthesis in hypothalamic astrocytes. J Neurosci. 2010 Sep;30(39):129507. 